\title{
Pumilio protects Xbp1 mRNA from regulated Ire1-dependent decay
}

\author{
Fatima Cairrao ${ }^{1}$, Cristiana C Santos ${ }^{1}$, Adrien Le Thomas², Scot Marsters ${ }^{2}$, Avi Ashkenazi ${ }^{2}$ and \\ Pedro M. Domingos ${ }^{1}$ \\ 1 - Instituto de Tecnologia Química e Biológica, Universidade Nova de Lisboa, Av. da República, 2780-157 Oeiras, Portugal \\ 2 - Cancer Immunology, Genentech, Inc., 1 DNA Way, South San Francisco, CA 94080, USA \\ Correspondence should be sent to domingp@itgb.unl.pt or cairrao@itgb.unl.pt
}

\section{SUMMARY}

The unfolded protein response (UPR) maintains homeostasis of the endoplasmic reticulum (ER). Residing in the ER membrane, the UPR mediator Ire1 deploys its cytoplasmic kinase-endoribonuclease domain to activate the key UPR transcription factor Xbp1 through non-conventional splicing of Xbp1 mRNA. Ire1 also degrades diverse ER-targeted mRNAs through regulated Ire1-dependent decay (RIDD), but how it spares Xbp1 mRNA from this decay is unknown. We identified binding sites for the RNA-binding protein Pumilio in the 3'UTR Drosophila Xbp1. In the developing Drosophila eye, Pumilio bound both the Xbp1 $1^{\text {unspliced }}$ and Xbp1 $1^{\text {spliced }}$ mRNAs, but only Xbp1 $1^{\text {spliced }}$ was stabilized by Pumilio. Furthermore, Pumilio displayed Ire1 kinase-dependent phosphorylation during ER stress, which was required for its stabilization of Xbp1spliced. Human IRE1 could directly phosphorylate Pumilio, and phosphorylated Pumilio protected Xbp1 $1^{\text {spliced }}$ mRNA against RIDD. Thus, Ire1-mediated phosphorylation enables Pumilio to shield Xbp1 ${ }^{\text {spliced }}$ from RIDD. These results uncover an important and unexpected regulatory link between an RNA-binding protein and the UPR.

\section{INTRODUCTION}

Metazoan cells respond to endoplasmic reticulum (ER) stress by activating an intracellular network of signaling pathways, known as the unfolded protein response (UPR) ${ }^{1,2}$. In higher eukaryotes, the UPR involves three ER transmembrane transducers: inositol-requiring enzyme 1 (IRE1), pancreatic ER kinase (PKR)-like ER kinase (PERK), and activating transcription factor 6 (ATF6). When misfolded proteins accumulate in the ER, IRE1 activates the downstream transcription factor X-box binding protein 1 (XBP1), via the non-conventional splicing of Xbp1 mRNA ${ }^{3-7}$. The cytoplasmic kinaseendoribonuclease domain of IRE1 mediates the splicing of a 26-nucleotides long intron from the Xbp1 mRNA, causing a frame-shift during translation that introduces a new carboxyl domain in the XBP1 protein. The resulting spliced form of Xbp1, XBP1spliced, is a functionally active transcription factor that upregulates the expression of ER chaperones and other UPR target genes ${ }^{8}$.

The intracellular localization, stability and translation of mRNAs is regulated by interaction of RNA-binding proteins (RBPs) or microRNAs with specific sequences present in the 3' untranslated regions (3'UTR) of the $m R N A^{9-11}$. In budding yeast, the 3'UTR of the Xbp1-orthologue Hac1 targets Hac1 mRNA to foci of activated IRE1 at the ER membrane, which enables IRE1-mediated splicing of Hac1 mRNA ${ }^{12}$. In contrast, in mammalian cells the 3'UTR of Xbp1 seems to be dispensable for the targeting of Xbp1 mRNA to activated IRE1 ${ }^{13}$. Instead, the targeting occurs through the tethering of 2 hydrophobic regions (HR1 and HR2) present in the XBP 1 unspliced protein to the cytosolic side of the ER membrane ${ }^{13,14}$. This latter process involves a tripartite complex comprising Xbp1 mRNA, a ribosome, and the nascent XBP1 protein, and additionally requires translational pausing of the $\mathrm{Xbp} 1^{\text {unspliced }} \mathrm{mRNA}^{14}$.

Besides Xbp1 mRNA splicing, the endoribonuclease (RNase) domain of Ire1 also performs a function known as regulated IRE1dependent decay (RIDD), which mediates the depletion of specific mRNAs ${ }^{15}$ and/or microRNAs ${ }^{16}$. While in Drosophila cells RIDD degrades ERtargeted mRNA relatively promiscuously, in mammalian cells it is thought to depend on a specific Xbp1-like mRNA sequence endomotif within a stem-loop structure, and on translational state of the mRNA target ${ }^{17}$. The phosphorylation and oligomerization state of IRE1 plays an additional role in controlling IRE1's RNase activity $^{18}$. RIDD can act as a post-transcriptional mechanism to deplete mRNAs, thereby affecting both ER homeostasis and cell fate ${ }^{19,20,21,22}$

RNA-binding proteins (RBPs) constitute an important class of post-transcriptional regulators. RBPs are involved in multiple critical biological processes, relevant to cancer initiation, progression, and drug resistance ${ }^{23}$. Several recent studies validate the role of the Pumilio family of RBPs in diverse biological processes in several 
organisms. Specific mRNA targets of two human Pumilio isoforms (PUM1 and PUM2) include oncogenes, tumor suppressors, and other factors implicated in oncogenic and cell death pathways ${ }^{24-}$ ${ }^{26}$. In several organisms, PUM proteins also play a conserved role in stem cell proliferation and selfrenewal ${ }^{27-30}$. PUM proteins are essential for development and growth, and their dysfunction has been associated with neurological diseases, infertility, movement disorders, and cancer ${ }^{31-36}$.

Drosophila Pumilio - the founding member of the PUM family - Is characterized as a translational repressor and is involved in embryo patterning, fertility and the regulation of neuronal homeostasis $^{31,37-40}$. PUM proteins act as posttranscriptional regulators, by interacting with consensus sequences called Pumilio regulatory elements (PRE) in the 3'UTRs of target mRNAs ${ }^{9}$ to modulate their translation and/or degradation ${ }^{41-42}$. Recent findings support a direct role of PUM proteins in the activation/protection of specific $\mathrm{RNAs}^{26}$. PUM proteins are composed of distinct functional domains: N-terminal repressor domains $(\mathrm{N})$, which are unique to different PUM orthologues, and a Pumilio homology domain (PumHD), which recognizes the PRE. These domains mediate the normal repressive role of PUM proteins by antagonizing the translational activity of $\operatorname{Poly}(\mathrm{A})$ binding protein (PABP) ${ }^{42,43}$. The PUM N terminus is required to fully rescue developmental defects of a pum mutant 44,45 .

Although much progress has been made toward understanding the biological roles of PUM proteins, it remains to be determined how they regulate their target mRNAs particularly under diverse biological conditions such as cellular stress. Here, we uncover an unexpected functional link between Pumilio and the Ire1-Xbp1 pathway. We show that Pumilio protects Drosophila Xbp1 against RIDD, without perturbing canonical Ire1-driven Xbp1 splicing. Furthermore, we provide evidence that Ire1 phosphorylates Pumilio under ER stress and that this is essential for Pumilio-mediated protection of Xbp1 mRNA. These results identify an important regulatory mechanism connecting RBPs and the UPR.

\section{RESULTS}

The 3'UTR of Xbp1 contains cis elements that regulate mRNA stability

The 3'UTRs of Drosophila Xbp1 $1^{\text {unspliced }}$ and $\mathrm{Xbp} 1^{\text {spliced }}$ differ in the length, the former being 600 bps longer than the latter (Fig. 1a). We conducted a search on the 3'UTR of Drosophila Xbp1 mRNA and identified two putative Pumilio regulatory elements (UGUAXAUA) (Fig. 1a,b). To test experimentally if these regions can regulate mRNA, we constructed reporters containing GFP, expressed under the control of the metalotheionin promoter ${ }^{46,47}$, together with the 3 'UTR of Xbp1 in wild type or a mutated version of each of the two PREs (Fig. 1b). To examine the impact of these PREs on mRNA stability, we mutated the sequence encoding the PRE (UGUAXAUA) to the nonfunctional element ACAAXAUA (Fig. 1b).

The mRNA decay of the resulting reporters was analyzed in transiently transfected Drosophila S2 cells, which were treated with actinomycin D to stop transcription. For each mutated version of the PREs the stability of the GFP reporter decreased as compared to the wild-type 3'UTR, suggesting a role for these regulatory regions in the posttranscriptional regulation of Xbp1. We also compared the effect of the $3^{\prime} U T R s$ of Xbp1 1 spliced and Xbp1 unspliced forms by quantitative RT-PCR, which showed a greater effect of the former 3'UTR on stability of the GFP reporter mRNA (Fig. S1). This result suggests that other, yet unidentified regulatory regions of RNA stability may be present in the 3'UTR of Xbp1 $1^{\text {unspliced. }}$

\section{Pumilio binds Xbp1 mRNA in the developing Drosophila eye}

To analyze if Pumilio could act as a regulator of Xbp1 in fly tissues, we expressed a transgene encoding a TAP-tagged ${ }^{48}$ Pumilio RNA-binding motif (UAS-TAP-PumHD), under control of the eyespecific GMR-GAL4 driver. We conducted TAP pulldown RNA affinity purifications (RPAs) from heads of transgenic adult flies with the genotype GMRGal4>UAS-TAP-PumHD, and performed RT-PCR to determine whether the endogenous Xbp1 mRNA was enriched in flies over-expressing TAP-Pum$\mathrm{HD}$. Xbp1 transcripts were strongly enriched in GMR-Gal4>UAS-TAP-PumHD flies as compared to UAS-TAP- PumHD controls (Fig. 1c,d). We found that Pumilio could bind equally well to the 3'UTR of Xbp1 unspliced and Xbp1spliced (Fig. 1d). These results suggest that endogenous Xbp1 transcripts in the Drosophila eye are subject to regulation by Pumilio.

\section{Pumilio regulates the stability of $\mathrm{Xbp} 1^{\text {spliced }}$ mRNA}

The activity of Ire 1 in mediating Xbp1 splicing can be assayed with an Xbp1-GFP reporter $^{49}$, wherein $\mathrm{Xbp} 1$ spliced is tagged with GFP. We constructed a new Xbp1 reporter (Xbp1-HA-GFP) (Fig. 2a), which distinguishes the translation product of Xbp1 unspliced, fused to an $\mathrm{HA}$ tag, from that of Xbp1 1 spliced, fused to GFP. We first tested the expression of the reporter translation products by western blot under non stress and stress conditions 
a

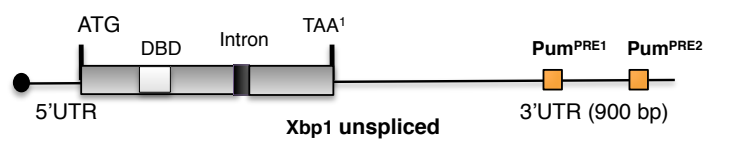

Non stress

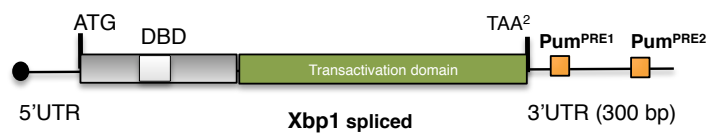

Stress

b

pRM GFP-Xbp1s 3'UTR

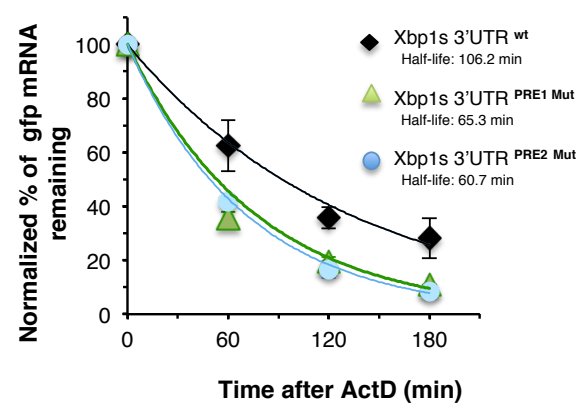

C

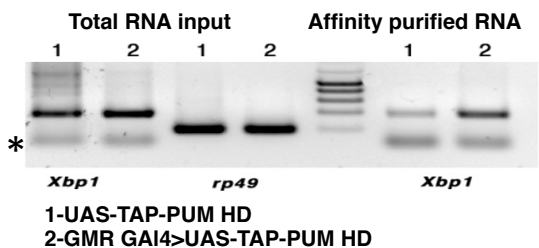

Pumilio binding sites

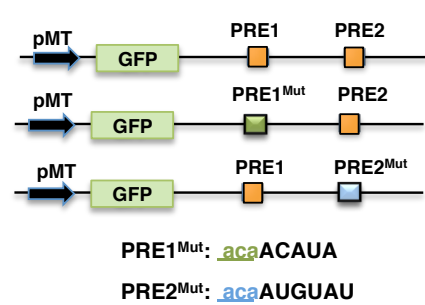

d

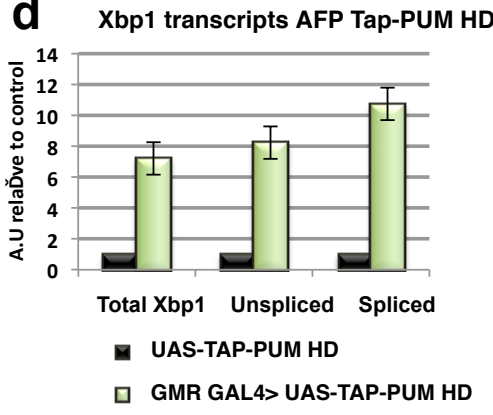

in the presence of dithiothreitol (DTT), an ER stress inducing chemical (Fig. 2b). In this context, PUM overexpression led to an increase in Xbp $1^{\text {spliced, }}$, but not Xbp1 $1^{\text {unspliced }}$ protein levels.

Subsequently, we determined the stability of the Xbp1-HA-GFP reporter mRNA in transiently transfected S2 cells, either with or without Pumilio RNAi depletion (Fig. 2c). Depletion of Pumilio decreased the stability of the Xbp1-HA-GFP reporter transcript as compared with controls (Fig. 2c). When Pumilio levels were restored by cotransfecting S2 cells depleted of Pumilio with a plasmid expressing either the full-length Pumilio protein ${ }^{50}$ or the Pumilio RNA binding domain (PumHD), the mRNA stability of Xbp1-HA-GFP reporter returned to the levels of the control experiment (no RNAi treatment), but it did so only when the fulllength protein was present (Fig. 2c). These results indicate that Pumilio has a protective role against degradation of the Xbp1 mRNA, and that although the HD region confers specific RNA interaction with the Xbp1 transcripts, the full-length Pumilio protein is required for its protective role.

\section{Preprint}

Figure 1- The 3'UTR of Xbp1 contains cis elements of mRNA stability

a) Schematic representation of Drosophila Xbp1 transcripts (unspliced and spliced). ATG (start codon), TAA (stop codon), DBD (DNA binding domain), Intron (23-nt hairpin structure recognized by IRE1 RNase domain. Two Pumilio regulatory elements (PRE1 and PRE2) are present in the 3' UTR.

b) Xbp1 3'UTR pRM GFP reporters bearing the WT and mutant PREs from the Xbp1 3'UTR. The consensus binding sites UGUA for Pumilio were mutagenized into ACAA for PRE $1^{\text {mut }}$ and PRE2 ${ }^{\text {mut; }}$ pMT, metallothionein promoter. Reporters were transiently transfected in S2 cells. Total RNA was isolated at different points following the addition of actinomycin $D(5 \mu \mathrm{g} / \mathrm{ml})$. Stability of the GFP reporters was assessed by quantitative RT-PCR (qRT-PCR), using primers specific for GFP and rp49 mRNAs (control). Levels of mRNA reporter were normalized to those of rp49 mRNA, and averages and standard deviations from three independent experiments are plotted.

c) TAP tag RNA affinity purification (AFP) from adult heads of transgenic flies expressing the Pumilio RNA-binding motif (GMR GAL4>UAS-TAP-PumHD) under the GMR driver (expression in eyes). Xbp1 transcripts are enriched in Pumilio RNA affinity purifications compared with controls (UAS TAPPumHD, but no GMR GAL4).

d) Quantitative RT-PCR using primers specific for Xbp1 1 spliced, Xbp1 1 Unspliced and total Xbp1 transcripts, from GMR GAL4>UAS-TAP-PumHD RNA pull downs, normalized against levels in the UAS-TAP-PumHD control pull downs. Results show a specific interaction between $\mathrm{Xbp} 1^{\text {Spliced }}$ and $\mathrm{Xbp} 1^{\text {Unspliced }}$ transcripts and PumHD.

\section{Pumilio regulates Xbp1 $1^{\text {spliced }}$ during photoreceptor differentiation}

Next we tested the regulation of Xbp1 mRNA by Pumilio in a physiological, developmental context. The Ire1 signaling pathway is activated during the pupal stages in the photoreceptors ${ }^{51}$, where it is required for photoreceptor differentiation and morphogenesis of the rhabdomere - the lightsensing organelle of photoreceptors. We generated transgenic flies with the Xbp1-HA-GFP reporter, and performed immunofluorescence analysis with antibodies against GFP and HA, to assess the expression levels of Xbp $1^{\text {spliced-GFP }}$ and

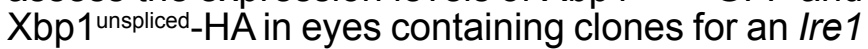
null mutation ${ }^{51}$. As expected, and validating the Xbp1-HA-GFP reporter, Xbp1 19liced_GFP expression was absent from cells homozygous for Ire1 mutation (labeled by the absence of DsRed), but Xbp1 1unspliced_HA expression was unaffected in Ire1 mutant cells (Fig. 2d). We next examined the expression of Xbp1-HA-GPF in eyes containing 
XBP1-HA-GFP-3'UTR mRNA

a

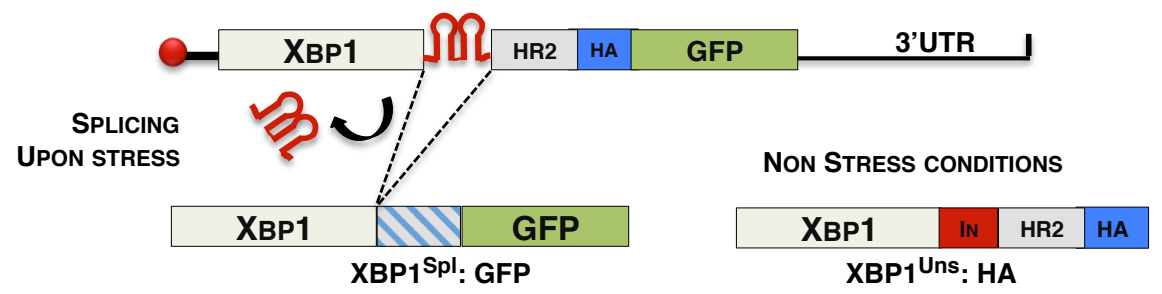

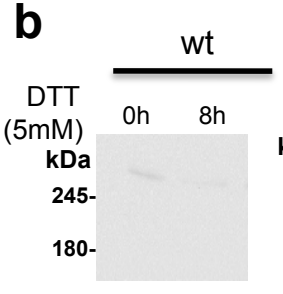
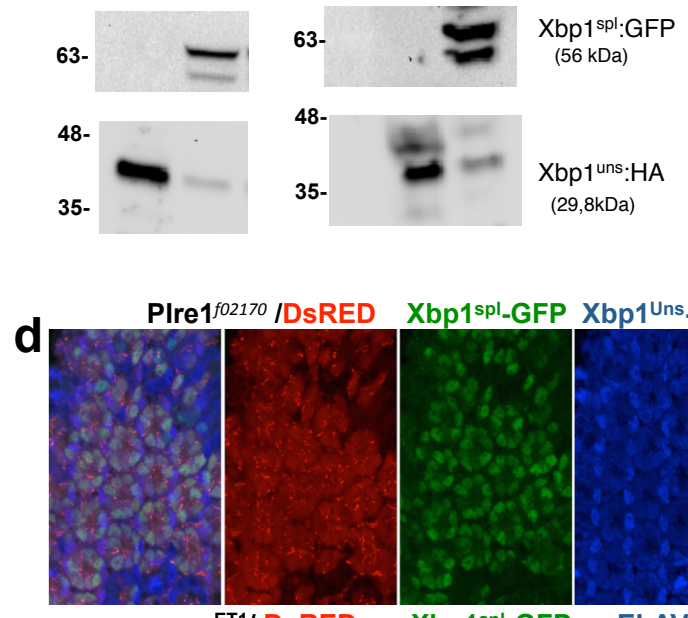

Xbp1 $1^{\text {spl_-GFP }}$ Xbp $1^{\text {Uns.HA }}$
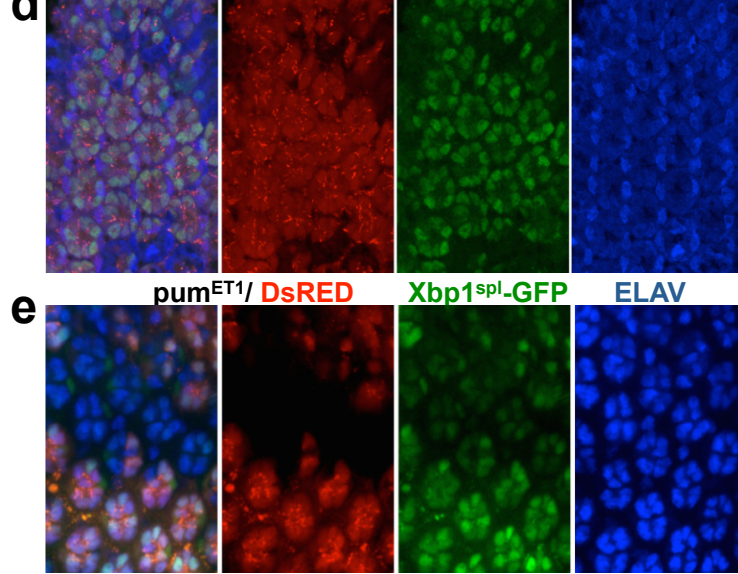

f
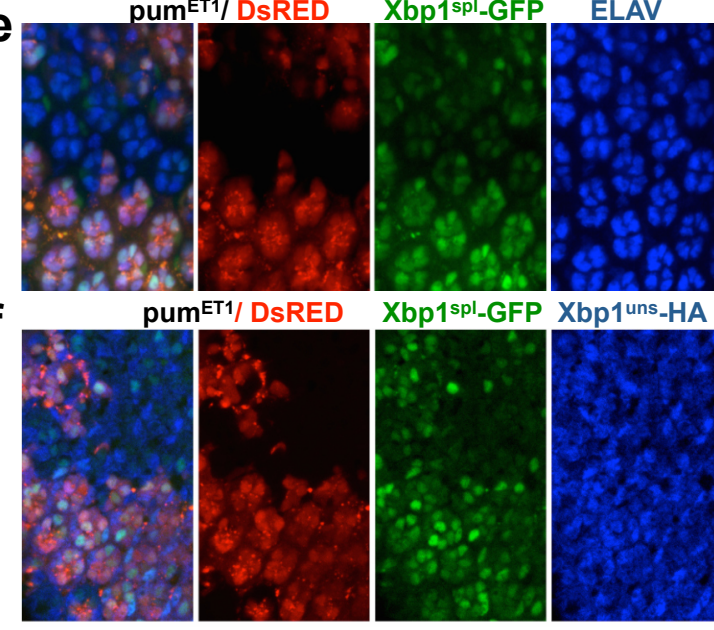

Xbp1spl-GFP Xbp1uns-HA

clones of the Pumilio null mutation pumET152. In pupal eyes $(50 \mathrm{hr})$, in the absence of Pumilio (labeled by the absence of DsRed), the expression of $\mathrm{Xbp} 1^{\text {spliced_GFP }}$ was reduced as compared to the wild type cells (Fig. 2e,f). However, expression of Xbp1 unspliced_HA remained unchanged (Fig. 2f), indicating that Pumilio exerts its regulatory role on

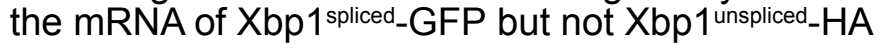

\section{C}

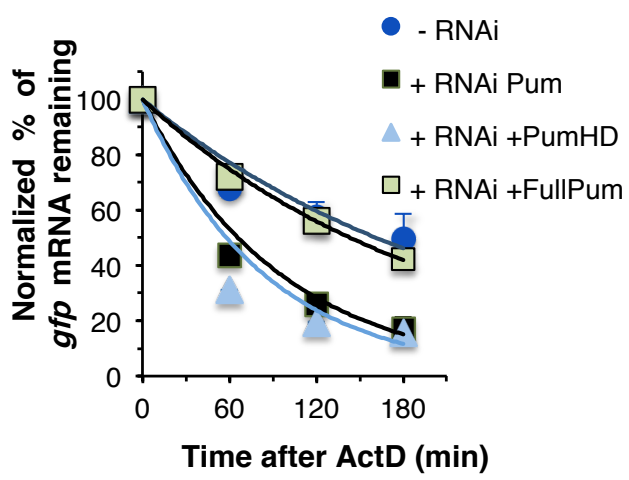

Figure 2-Pumilio regulates the stability of $X b p 1^{\text {spliced }} m R N A$ a) Schematic representation of the Xbp1-HA-GFP reporter construct. This reporter allows the detection of XBP1 1 spl (Spliced) and Xbp 1 Uns(Unspliced) forms. The pUAST-Xbp1-HA-GFP reporter, contains an HA tag fused in frame with the coding sequence of Xbp1 Unspliced. GFP only gets in frame with Xbp1 $1^{\text {spliced }}$ after Ire1 mediated splicing of the $23 \mathrm{bp}$ intron.

b) Expression of Xbp1-HA-GFP reporter in S2 cells under non stress (Oh) and stress conditions (8h DTT treatment). Xbp1 ${ }^{\text {spl }}$ GFP $(56 \mathrm{kDa})$ is detected under stress conditions. Overexpression of Pumilio (Pum-V5) increases the levels of

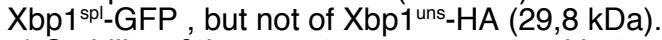

c) Stability of the reporter was compared between non-treated S2 cells (-RNAi) and RNAi treated cells (+RNAi) against Pumilio. Inactivation of Pumilio by RNAi destabilizes Xbp1 ${ }^{\text {spl_ }}$ GFP reporter (black squares). Reposition of Pumilio levels by transfection with full length Pumilio (Full Pum, green squares) restores the stability of the GFP reporter in S2 cells, in contrast to the RNA binding domain of Pumilio (PumHD, blue triangules). Total RNA was extracted after induction of stress with DTT (4h at $5 \mu \mathrm{M})$ and mRNA stability was analysed by quantitative RT-PCR at defined periods after actinomycinD treatment $(5 \mu \mathrm{g} / \mathrm{ml})$.

d) The Xbp1-HA-GFP signaling reporter is activated in the Drosophila photoreceptors during midpupal stages (50 hrs).

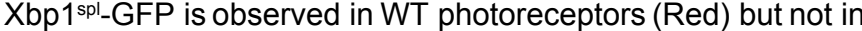
photoreceptors that are homozygous for an Ire1 null mutation $\left(\mathrm{Plre} 1^{102170}\right)$, labeled by the absence of DsRed. Xbp1 $1^{\text {uns }}-\mathrm{HA}$ (blue) is observed in all cells.

e) The expression of Xbp1spl-GFP (green) is reduced in cells homozygous for the Pum null mutation (PumET1), labeled by the absence of DsRed expression, in comparison with wildtype cells (DsRed positive). Elav (blue) was used as a marker of the photoreceptors.

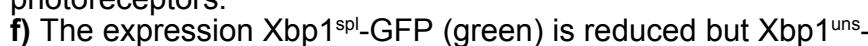
$\mathrm{HA}$ (blue) is unaltered in cells homozygous for PumET1, labeled by the absence of DsRed expression, in comparison with wildtype cells (DsRed positive), indicating that the regulatory role of Pumilio is only on the $\mathrm{Xbp} 1^{\mathrm{Spl}}$ form. Anti-HA was used to label Xbp1 $1^{\text {Uns. }}$ HA protein. 


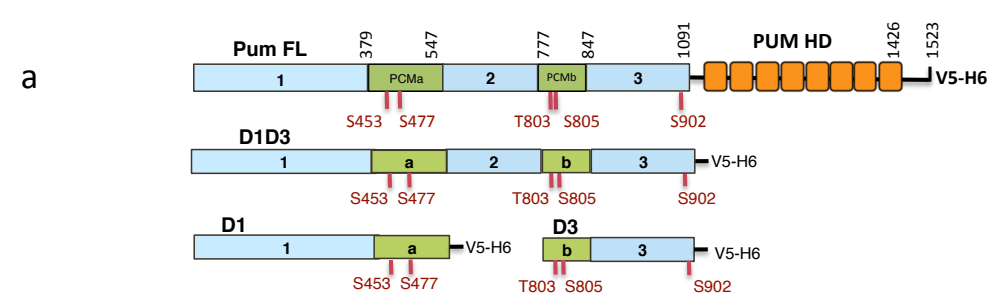

b

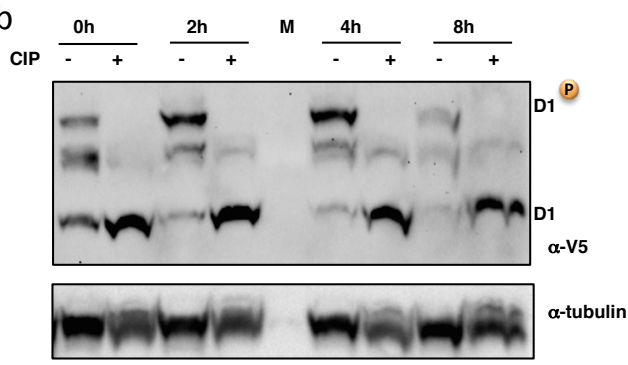

C

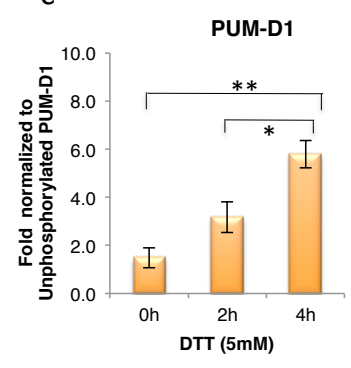

d
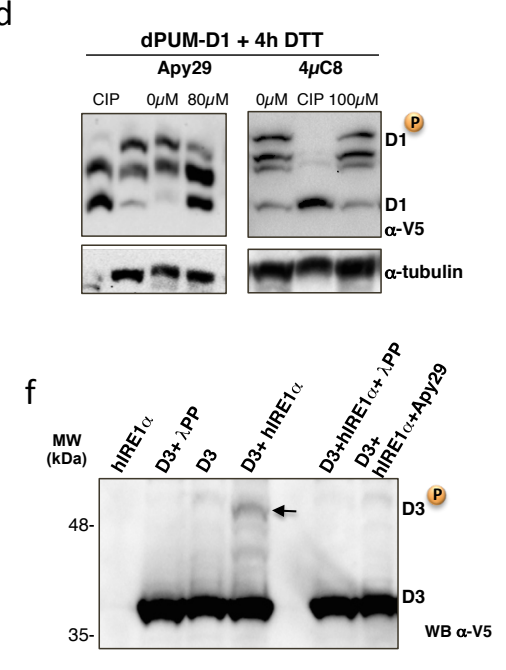

in vitro dPUM-D3 Phostag e $\quad$ DPUM-D $3+4 h$ DTT
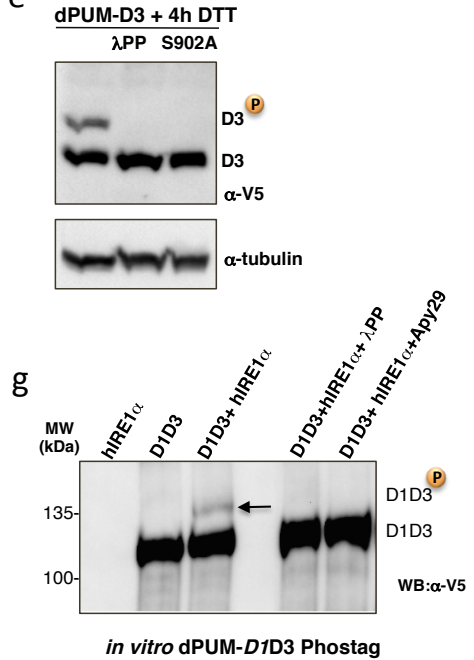

\section{Pumilio undergoes IRE1 kinase-dependent} phosphorylation during ER stress

It is known that Pumilio proteins may change their activity according to their phosphorylation state ${ }^{53}$. Furthermore, the observation that the stability of the Xbp1 1 spliced transcript was dependent of the fulllength Pumilio protein (Fig. 2c) indicated that other domains of Pumilio, besides the RNA-binding domain, are also important for Xbp1 mRNA stability. Recent studies ${ }^{36,42,50}$ indicate that additional regions in the $\mathrm{N}$ terminus of Pumilio act as repressor domains, with two specific segments - designated Pumilio conserved motif (PCM) a and $b$ - being found in both Drosophila and human PUMs (Fig. 3a and Fig. S2a). We screened the Pumilio protein sequence for potential serine/threonine phosphorylation sites using online bioinformatic tools $^{54}$ combined with phosphorylation sites reported in other screens (http:// www.phosphosite.org/). We found potential phosphorylation sites across the different domains
Figure 3 - Pumilio undergoes Ire1 kinasedependent phosphorylation during ER stress a) Diagram of Drosophila Pumilio domains, with possible phosphorylation sites identified in Phosphosite (www.phosphosite.org and Phosida (http://www.phosida.com). Indicate below in red for each amino acid residue. Truncated version of the full-length Pumilio protein were constructed carrying different domains of Pumilio (Pum FL: Full length protein, D1D3: domain 1 to 3, D1: domain 1, D3: domain 3, PUM-HD: RNA binding Pumilio homology domain. Constructs are tagged with V5 and 6xHis at their $\mathrm{C}$-terminal end. The motifs represented by letters $a$ and $b$ refer to conserved motifs (PCMa and $\mathrm{PCMb}$ ) in Drosophila and human PUM proteins.

b) Drosophila S2 stable cell lines expressing the V5 tagged Pumilio D1 were submitted to ER stress (DTT $5 \mathrm{mM}$ ) and samples collected at defined times before (Oh) and after stress induction (2h, $4 \mathrm{~h} 8 \mathrm{~h})$. Phosphorylation of Pumilio domains was determined based on changes in their electrophoretic mobility through a standard SDSPAGE gel using the Phostag compound [50mM]. Pumilio proteins were detected by immunoblot (IB) with a mouse monoclonal V 5 antibody. The mobility shift of Pumilio is specific for phosphorylation as it is reversed by calf intestinal phosphatase treatment $(+\mathrm{CIP})$. Total protein levels were monitored by tubulin levels. D1P: hyper-phosphorylated forms, D1: non phosphorylated form of D1. M: protein size markers.

c) Quantification of fold increase of PUM D1 ${ }^{\mathrm{P}}$ during ER stress, normalized to non phosphorylated form (D1). The statistical significance was calculated by one-way ANOVA coupled with Tukey's post hoc test $\left({ }^{\star} p<0.05 ;{ }^{* *} p<0,01\right)$

d) An inhibitor of Ire1 kinase activity impairs the phosphorylation of dPUM-D1. Immunoblot (IB) with Phostag phosphorylation analysis of Pumilio D1 after ER stress (4h DTT treatment). Cells were incubated with an inhibitor of Ire1 kinase activity (APY29, $80 \mu \mathrm{M}$ ) or an inhibitor of IRE1 RNase activity $(4 \mu 8 \mathrm{c}, 100 \mu \mathrm{M})$. The phosphorylation pattern of dPUM-D1 was monitored by IB with anti-V5 antibody. Total protein loading was monitored by levels of tubulin. CIP (alkaline phosphatase treatment of cell extracts after $4 \mathrm{~h}$ of DTT treatment. e) Phostag immunoblot (IB) for phosphorylation analysis of Pumilio Domain 3 (dPUM-D3) after ER stress (4h DTT treatment). dPUM-D3 was detected by IB using anti-V 5 antibody. Total protein loading was monitored by levels of Tubulin. Mutation of site Ser902 to Ala (S902A) prevents the DTT induced phosphorylation of dPUM-D3. $\lambda$ PP: $\lambda$ phosphatase treatment of cell extracts after $4 \mathrm{~h}$ of DTT treatment. f, g) Phostag immunoblot (IB) after in vitro phosphorylation assay with purified domains of Pumilio (D3 and D1D3) incubated with human IRE1-alpha [464-977] in kinase buffer (2mM ATP). Controls: IRE1 alone, PUM alone (D3 or D1D3); Inhibition of phosphorylation was observed upon treatment with $\lambda$-phosphatase or the Apy 29 Ire1 kinase inhibitor. Pumilio proteins were detected with anti-mouse $\mathrm{V} 5$ antibody .

of Pumilio (Fig. 3a). To investigate if Pumilio is phosphorylated during ER stress, we conducted Phostag analysis using Pumilio proteins tagged with a C-terminal V5 epitope (Fig. 3a). It was difficult to analyze phosphorylation of full-length Pumilio ${ }^{50}$, due to its relatively large size of $\sim 180 \mathrm{kDa}$ 
(data not shown). Therefore, to facilitate the analysis, we constructed 3 truncated versions of V5-tagged Pumilio (D1= aa 1 to 547; D3= aa 77 to 1091 and D1D3= aa 1 to 1091), which contained the predicted phosphorylation sites.

Phostag analysis revealed that, during ER stress (4 hr DTT), Pumilio D1 displayed a 6-fold increase in phosphorylated forms, relative to nonER stress conditions ( $0 \mathrm{hr}$ DTT) (Fig. 3b). This phosphorylation pattern was confirmed by treatment with phosphatases (+CIP or $+\lambda P P)$, which reverted Pumilio to a non-phosphorylated state (Fig. 3b).

During ER stress and after Ire1 transautophosphorylation, the cytosolic kinaseendoribonuclease domain of IRE1 rotates to a back-to-back configuration ${ }^{2,18}$, possibly allowing the kinase active site to access other potential substrates. We reasoned that through binding to the 3'UTR of Xbp1, Pumilio may localize to the vicinity of the Ire1 kinase domain. Therefore, we tested whether Ire1 could phosphorylate Pumilio during ER stress, using the inhibitors of Ire1 kinase activity (Apy 29) ) $^{55}$ and compound \#18 ${ }^{56}$ or an inhibitor of IRE1 RNase activity $(4 \mu 8 C)^{57}$. Upon DTT exposure (4 hr), in S2 cells transfected with PUM-D1, Apy 29 attenuated the generation of PUM-D1 hyper-phosphorylated forms (Fig. 3d). In contrast, $4 \mu 8 \mathrm{C}$ did not change the pattern of PUMD1 phosphorylation, which is expected as $4 \mu 8 \mathrm{C}$ is specific for the RNase activity and does not inhibit IRE1 kinase activity ${ }^{57}$. We also observed ER stress induced phosphorylation of PUM-D3, and by constructing phosphorylation site mutant versions of PUM-D3 we could identify S902 as a site that is phosphorylated under ER stress conditions (Fig. 3e).

\section{hIRE1 phosphorylates Pumilio and hPUM1}

To confirm that IRE1 kinase activity could directly phosphorylate Pumilio, we performed in vitro kinase reactions using the hIRE1alpha kinaseendoribonuclease (KR) domain ${ }^{57}$ and purified versions of Pumilio domains D3 and D1D3. Phostag immunoblot analysis (Fig. 3f,g) showed specific bands indicating phosphorylation of PUMD3 and PUM-D1D3 upon incubation with hIRE1 KR. Pumilio phosphorylation was abolished upon Apy 29 or $\lambda$-PP treatment. To complement these results, we performed in vitro radioactive kinase assays using hIRE1 KR and purified versions of Pumilio and hPum1 protein domains (Fig. 4a,b and Fig. S2b). The hIRE1 KR protein phosphorylated both Pumilio and hPum1 proteins. For negative controls, we used a kinase-dead hIRE1 KR as enzyme, or BIP (a luminal ER protein that should not be a direct target for IRE1 phosphorylation) as substrate (Fig. S3a). Furthermore, to assure that the phosphorylation pattern observed for the PUM proteins in the radioactive assays did not simply
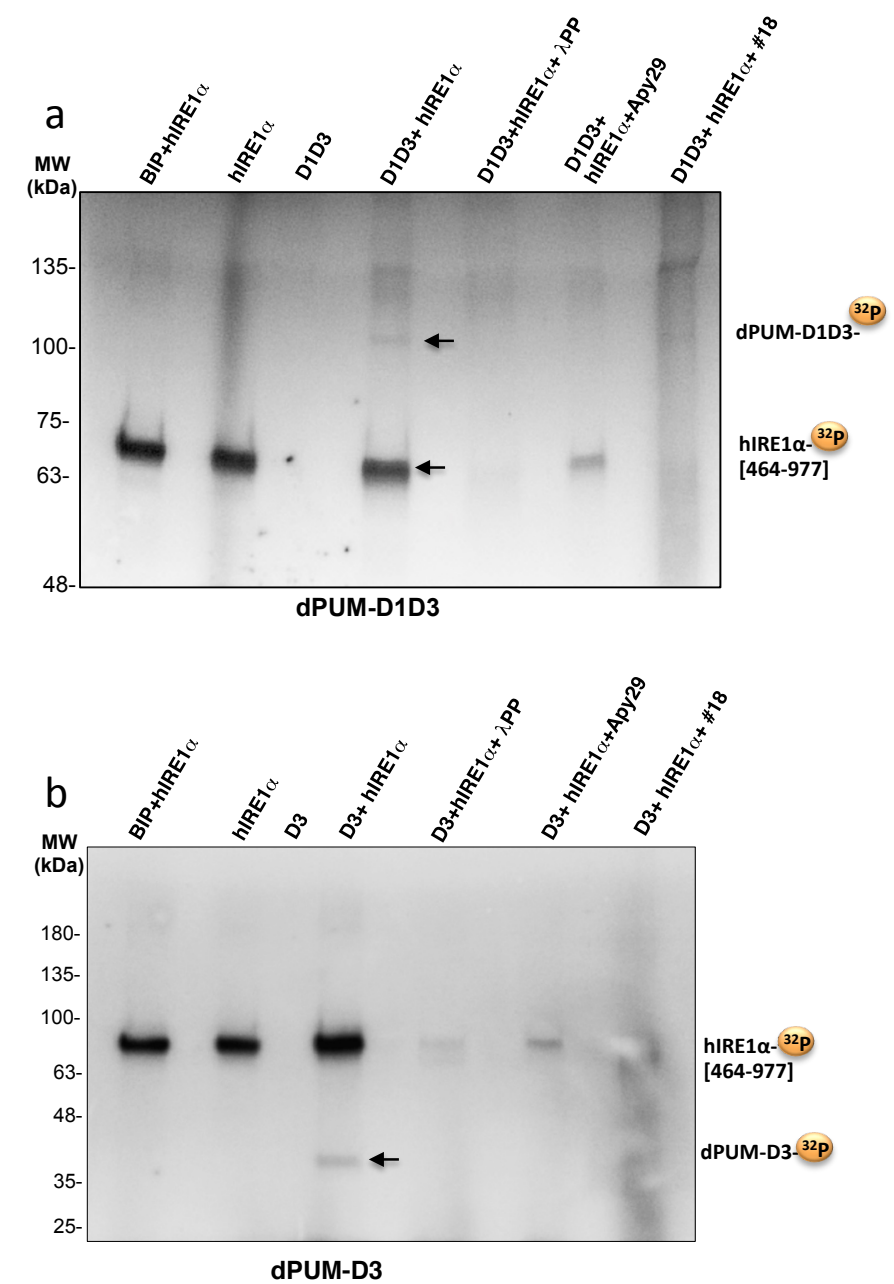

Figure 4- hIRE1 KR phosphorylates Pumilio in vitro

a and $\mathbf{b})$ In vitro radioactive phosphorylation assays of purified Pumilio dPUM-D1D3 (a) and dPUM-D3 (b) with hIRE1 KR (464-977). Purified proteins were incubated $2 \mathrm{~h}$ in IRE1 kinase buffer containing $\gamma$-ATP $\left[{ }^{32} \mathrm{P}\right]$. Detection of radioactive dPUMD1D3, dPUM-D3 and auto-phosphorylation of hIRE1 KR are denoted by a yellow bullet ${ }^{32} \mathrm{P}$. Negative controls: BIP as a luminal ER protein non-phosphorylated by IRE1, and proteins without incubation with IRE1. Specificity of phosphorylation was monitored by treatment with lambdaPP or incubation with specific inhibitors of IRE1 kinase activity (Apy 29 and compound \#18). MW: protein molecular weights in $\mathrm{kDa}$.

reflect IRE1 auto-phosphorylation, we used an antibody specific for phosphorylated IRE1. While we observed phosphorylated monomers, dimers and oligomers of hIRE1 KR as expected, we could not detect any signal in the $40 \mathrm{KDa}$ region (Fig. $\mathrm{S} 3 \mathrm{~b}$ ), which corresponds to the phosphorylated forms of Pumilio that were detected with the V5 antibody (Fig. 4b). These results show that hIRE1 KR can directly phosphorylate Pumilio. 
a

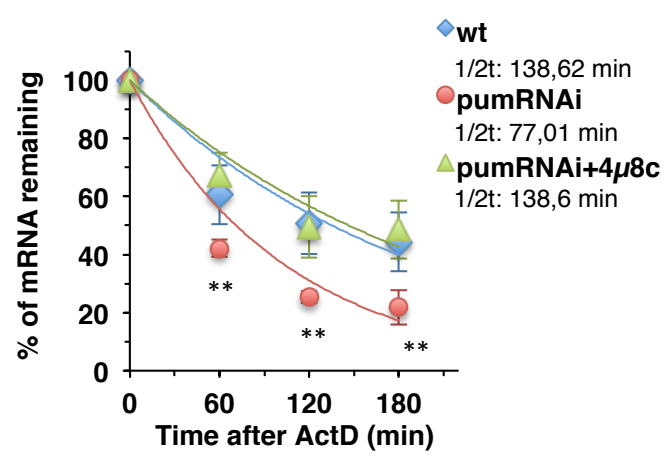

C

dPUM-FL vs Phosphomutants

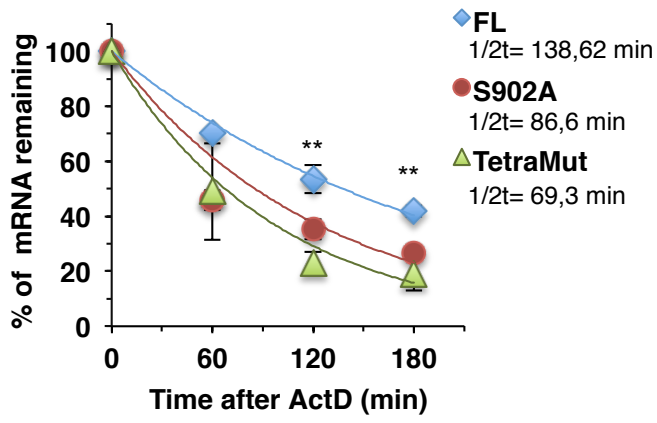

\section{Pumilio protects $\mathrm{Xbp} 1 \mathrm{mRNA}$ from regulated IRE1-dependent decay}

We have shown that Pumilio has a protective role in the stability of Xbp1 mRNA (Fig. 2c). Ire1 can also mediate RIDD, the selective decay of ERbound mRNAs, thereby reducing the load of nascent proteins entering the ER in order to be folded $^{58}$. RIDD plays an import role during persistent ER stress ${ }^{19}$ and in Drosophila cells it can lead to the complete degradation of even ectopic mRNAs, such as GFP ${ }^{15,59}$. We therefore hypothesized that Pumilio may protect Xbp1 mRNA from decay by Ire1 under ER stress conditions. To test this possibility, we performed mRNA stability assays with the Xbp1-HA-GFP reporter in S2 cells treated with DTT, in the absence or presence of the Ire1 RNase inhibitor $4 \mu 8 \mathrm{C}$. The destabilization of Xbp1-HA-GFP mRNA in cells depleted of Pumilio was reverted upon $4 \mu 8 \mathrm{C}$ treatment (Fig. 5a), indicating that Pumilio stabilizes Xbp1 mRNA against the RNase activity of Ire1.

We also conducted mRNA stability assays using in vitro transcribed Drosophila Xbp1 mRNA incubated with hIRE1 KR. Since we could not produce purified recombinant full-length Pumilio, we used different forms of hPUM1, which were pre-incubated with the Xbp1 transcript in order to assess their protection against degradation by IRE1 (Fig. 5b). Full-length

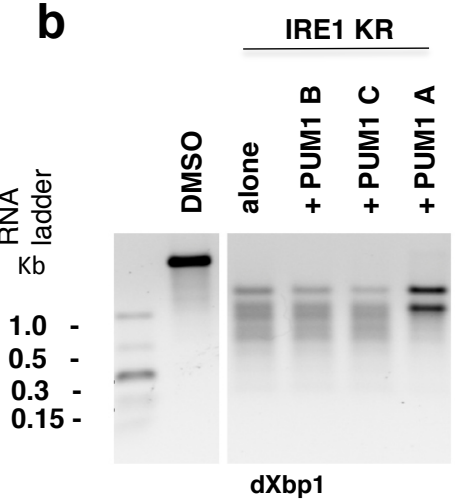

PUM1 B= 2-827 fragment Human PUM

PUM1 C= 828-1186 fragment Human PUM

PUM1 $A=2-1186$ Full human PUM

Figure 5 - Pumilio protects $\mathrm{Xbp} 1^{\text {spliced }}$ mRNA from regulated Ire1-dependent decay

a) WT S2 cells were compared to cells treated with RNAi against Pumilio (pumRNAi) and with or without $4 \mu 8 \mathrm{c}[100 \mu \mathrm{M}]$, an inhibitor of IRE1 RNase activity. Following ER stress induction (5mM DTT), and in the presence ActinomycinD $[5 \mu \mathrm{g} / \mathrm{ml}]$, total RNA was isolated from cell extracts at different periods. The levels Xbp $1^{\text {spliced-GFP }} \mathrm{mRNA}$ were normalized to rp49 mRNA levels, and the half-lives calculated by regression analysis of amount of \%mRNA remaining against time (min). qRT-PCR analysis was used to determine mRNA levels using specific primers for $g f p$ and $r p 49$. Averages of $\%$ mRNA remaining and corresponding standard deviations were calculated from at least 3 independent experiments. The statistical significance was calculated by one-way ANOVA coupled with Tukey's post hoc test $\left({ }^{*} p<0.05 ;{ }^{*} p<0,01\right)$.

b) In vitro transcripts of $\mathrm{dXbp} 1$ were incubated with purified hIRE1 KR. Human PUM1 FL protects Xbp1 RNA from Ire1 dependent decay, but does not impair Ire1 dependent Xbp1 splicing. $\mathrm{dXBP} 1=$ Drosophila XBP1 T7 transcript, hPUM1 B = [2-827] fragment Human PUM; hPUM1 $C=[828-1186]$ fragment Human PUM, hPUM1 A= [2-1186]; 3P-IRE1 = phosphorylated IRE1.

c) qRT-PCR results from Pumilio RNai treated $\mathrm{S} 2$ cells transfected with plasmid expressing dPUM-FL, a single or a quadruple phosphomutant of dPUM-FL (full length Pumilio containing the single mutation S902A; and a quadruple mutant: T537A, S540A, S544A, S902A). The Pumilio protective role upon $\mathrm{Xbp} 1^{\text {spliced-GFP }}$ is diminished in the dPUM-FL phosphomutants. The statistical significance was calculated by one-way ANOVA coupled with Tukey's post hoc test $\left({ }^{*} p<0.05\right.$ $\left.;{ }^{* *} p<0,01\right)$.

hPUM (hPUM1-FL) protected the Xbp1 mRNA from degradation by hIRE1 KR, but did not block or even diminish the hairpin motif-dependent splicing of Xbp1 mRNA. By contrast, hPUM1-B (2-827) did not protect Xbp1 mRNA from decay, consistent with the absence of the HD region necessary for binding to Xbp1 mRNA in this hPUM variant. Likewise hPUM1-C (828-1186) is incapable of such protection. Only the full-length hPUM1 protein contains all the requisite domains for protection of Xbp1 mRNA, in keeping with the above results (Fig. 2c). 


\section{Preprint}

\section{Pumilio's protection of Xbp1 mRNA is dependent on its phosphorylation state}

Having identified $\mathrm{S} 902$ as a site of Pumilio phosphorylation under ER stress (Fig. 3e), we next asked if the phosphoryation status of Pumilio could regulate the effect on the stability of $\mathrm{Xbp} 1$ spliced. To examine this, we compared the half-life of Xbp1 upon overexpression of wt Pumilio or Pumilio phosphomutants (S902A and a quadruple mutant: S902A,T537A, S540A, S544A) in RNAi Pumiliodepleted S2 cells (Fig. 5d). As compared to wild type Pumilio, overexpression of the phosphomutants lead to a decrease in the stability of Xbp1 spliced, demonstrating that Pumilio phosphorylation is required to promote its protective effect on Xbp1 transcripts under ER stress.

\section{DISCUSSION}

Our results uncover a novel protective effect of Pumilio on Xbp1 mRNA during ER stress. This protective effect depends on the phosphorylation status of Pumilio, which can be mediated by Ire1 kinase activity in response to ER stress. We propose a model depicted in Fig. 6, which involves 3 steps.

In the absence of ER stress, Ire1 is not active and Xbp1 mRNA is not spliced, but Pumilio can bind the 3'UTR of Xbp1 ${ }^{\text {unspliced }}$ mRNA (Fig. 6 1). Indeed, our RNA pull down experiment (Fig. 1d) showed that Pumilio can bind equally well to the 3'UTR of Xbp $1^{\text {unspliced }}$ and Xbp1 $1^{\text {spliced. }}$. Accumulation of misfolded protein in the lumen of the ER causes ER stress and activates Ire1. At this stage, in order to be spliced, Xbp1 mRNA must localize in the vicinity of the cytoplasmic domain of Ire1, which harbors both kinase and endoribonuclease activity. Upon ER stress, Pumilio is phosphorylated via a mechanism that requires Ire1 kinase activity (Fig. 3). As demonstrated by our in vitro assays (Fig. 4), the kinase domain of Ire1 can directly phosphorylate Pumilio; however, we cannot exclude at this stage the possibility that other kinases also may contribute to Pumilio phosphorylation. It is known that phosphorylation of Pum family proteins contributes to their activation and function ${ }^{53}$. We suggest that in this case, Ire1dependent phosphorylation of Pumilio causes a conformational change in the mode of interaction between Pumilio and Xbp1 mRNA, such that much of the transcript, though not the canonical stemloop structures, is inaccessible to the more promiscuous endoribonuclease activity of Ire1 (Fig. 6: step 2). This allows Xbp1 splicing to occur and furthermore permits Ire1 to carry out RIDD while sparing Xbp1 1spliced mRNA and allowing its more efficient translation (Fig. 6 - 3).

We do not know if Pumilio also protects Xbp1 mRNA from other ribonucleases and for how

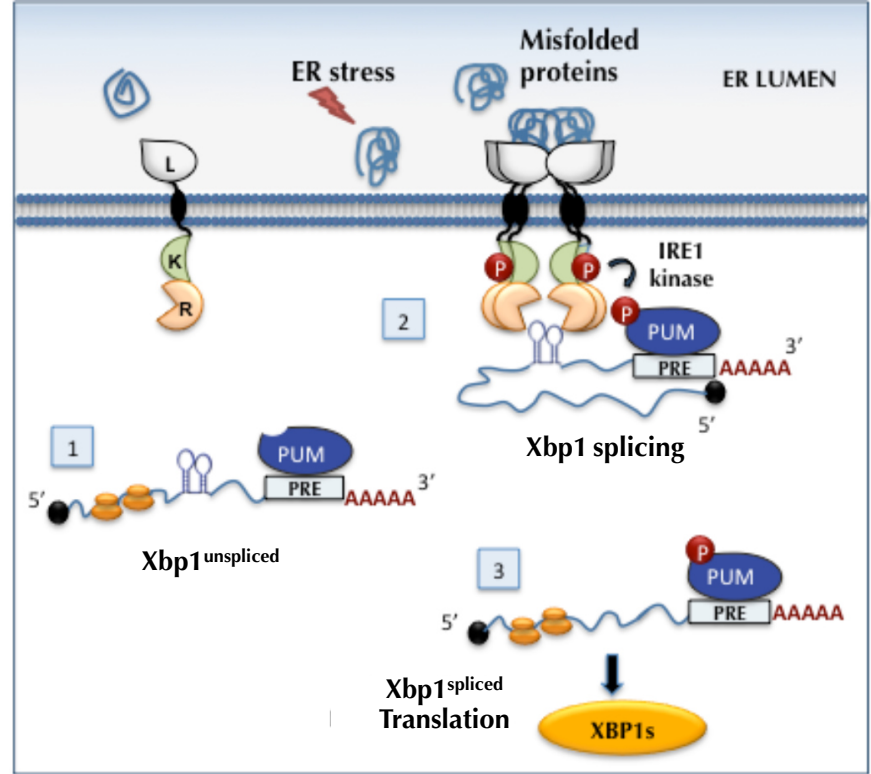

Figure 6- Model for Ire1-controlled post-transcriptional regulation of Xbp1 by Pumilio.

Step 1- In non ER stress conditions, Xbp1 1unspliced is present in the cytosol and PUM may bind to the PRE elements in the Xbp1 3'UTR; Step 2- ER stress conditions lead to Ire1 autophosphorylation and Pumilio phosphorylation. Phosphorylated Pumilio protects Xbp1 $1^{\text {spliced }}$ mRNA from Ire1 dependent decay, but does not impair Ire1 dependent Xbp1 splicing. Step $3-X b p 1^{\text {spliced }}$ transcripts can be efficiently translated into the $\mathrm{Xbp} 1^{\text {spliced }}$ transcription factor.

long the protective effect against RIDD lasts. Other studies have shown ${ }^{60}$, using cultured mouse cells, an increase in the stability of mRNA Xbp $1^{\text {spliced }}$ at a time of translational repression during "early" phases of ER stress ( $4 \mathrm{hr}$ treatment with DTT). These authors suggested that Xbp1 spliced mRNA could be protected from degradation by an unidentified protein factor. Our results suggest that Pumilio is such factor, while Ire1 RIDD activity is the degradation-causing agent.

From our model, we also predict that upon overcoming ER stress conditions, Pumilio phosphorylation levels will be reduced, either due to the activity of phosphatases and/or due to Ire1 dephosphorylation and attenuation ${ }^{61}$. At this stage, Pumilio's protective role over Xbp1 mRNA may subside, presumably making the transcript more vulnerable to the action of the mRNA decay machinery and the ribosome-associated quality control, as previously shown for $\mathrm{Hac}^{162}$. This regulatory step may avoid an accumulation of Xbp1 1 spliced under non stress conditions, which could be detrimental for cellular homeostasis.

Previous studies have shown that Pumilio proteins play a translational repressive role or promote degradation of their target mRNAs, which is in contrast with our results. However, another study has shown that, contrary to the canonical repressive activity, PUM1/2 rather promote FOXP1 expression through direct binding to two consensus PREs present in the FOXP1-3'UTR ${ }^{63}$. Furthermore, 
an additional report has identified RNAs that are positively regulated by human PUM1 and PUM2 ${ }^{64}$. Our results demonstrate that Ire1 is responsible for the phosphorylation status of Pumilio during ER stress and that this phosphorylation has implications for Xbp1 1 spliced protein levels. Recent data in zebrafish implicate Pum1 phosphorylation as an initial key step for the sequential activation of cyclinB1 mRNA translation during oocyte maturation, although the kinase involved remains unidentified ${ }^{65}$. In Xenopus, Nemo-like kinase (NLK) - a typical mitogenactivated protein kinase that is activated during an early phase of oocyte maturation ${ }^{66}$ - was shown to directly phosphorylate Pum1 as well Pum2 in vitro. It is possible that other kinases may be involved in Pumilio phosphorylation under non-ER stress conditions or specific developmental stages.

In conclusion, our present work uncovers an unanticipated mechanism that regulates one of the key branches of the UPR through the action of an RBP. This involves Ire1-kinase-driven phosphorylation of Pumilio, which in turn protects Ire1-RNase-driven Xbp1 ${ }^{\text {spliced }}$ against RIDD, thereby coordinating the two major endoribonuclease outputs of IRE1 to enable a more efficient intracellular response and ER stress mitigation.

\section{METHODS}

\section{Cell culture}

Drosophila S2 cells (Schneider, 1972) were cultured at $25^{\circ} \mathrm{C}$ in Schneider's Drosophila medium (Invitrogen) supplemented with $10 \%$ heat inactivated fetal bovine serum (FBS, Invitrogen), $2 \mathrm{mM}$ glutamine (Invitrogen), $100 \mathrm{U} / \mathrm{mL}$ penicillin and 100 $\mu \mathrm{g} / \mathrm{mL}$ streptomycin (Invitrogen).

\section{Transgenic flies}

Transgenic lines were generated using pUAST-AttB and phiC31 integrase-mediated DNA integration (BestGene) that allows the insertion of the transgenes in a specific site of the acceptor fly genome. Clones of mutant eye tissue were generated by the FIp/FRT technique ${ }^{67}$, with Flipase expression under the control of the eyeless promoter. Drosophila stocks obtained from the Bloomington Stock Center (Indiana University, Bloomington, IN, USA): GMR-Gal4 (active in the eye, under the control of the glass multiple reporter); eye-flip GMR-Gal4 (promotes recombination in the eye) and Actin5cGal4 (ubiquitous expression). Drosophila stocks were maintained at $25^{\circ} \mathrm{C}$ on standard cornmeal media in an incubator with a $12 \mathrm{~h}$ light/dark cycle. TAP-PUM stocks were a kind gift from André Gerber Laboratory.

\section{Plasmid construction}

The 3 'UTRs of Xbp1 $1^{\text {spliced }}$ and Xbp1 $1^{\text {unspliced }}$ forms were amplified from the cDNA clone GH09250 (Flybase) using specific primer pairs, and cloned downstream of the green fluorescent protein (GFP) coding sequence in the vector pRmHa, containing the metallothionein promoter. The mutations in the Pumilio binding sites were introduced using oligonucleotide-mediated sitedirected mutagenesis and inverse PCR. The UAS-Xbp1-HAGFP-3'UTR constructs were made by PCR cloning. All cloning was performed with the Phusion High-Fidelity PCR Master Mix with HF Buffer or GH Buffer according to the manufacturer's protocol. All clones were confirmed by sequencing (Stabvida). The full-length Pumilio protein with a C-terminal V 5 tag $^{50}$ was a gift from Aaron Goldstrohm, from which the different truncated dPUM-D1, dPUM-D3 and dPUM-D1D3 were constructed.

\section{Transfection and stable cell line establishment}

Cells were co-transfected with the different plasmids using Effectene reagent according to manufacture indications (Qiagen). For stable transfection, cells were selected by replacing Schneider's complete Drosophila media with fresh medium supplemented with the appropriate antibiotics (zeocin, puromycin) according to the resistance gene present in the transfected plasmids and maintained under selective media until the formation of resistant clones.

\section{Total RNA and protein extraction}

For RNA stability and Western blot experiments, $4,5 \times 10^{5} \mathrm{~S} 2$ cells were seeded in 12-well plates the day before treatments, transfections and protein or RNA extraction. Transfection was performed with Effectene (Qiagen) according to the manufacturer's instructions. Expression of the GFP reporter under the metallothionein promoter was induced by adding 7 $\mathrm{mM} \mathrm{CuSO}_{4}$ to the cell culture media for $3 \mathrm{hrs}$. For the UAS dependent ${ }^{4} \mathrm{Xbp} 1$ reporters, transcription was induced by cotransfection of Actin-Gal4 plasmid. For mRNA half-life measurements, transcription was blocked with actinomycin $D$ $(5 \mathrm{\mu g} / \mathrm{ml}$; Sigma-Aldrich) and the cells were harvested at the indicated time points. Total RNA was then extracted using Zymo Research quick-RNA miniprep Kit.

\section{qPCR and RT-PCR}

Primers for QRT-PCR analysis were designed according to MIQE guidelines (Minimum Information for Publication of qRTPCR Experiments) using NCBI primer blast, choosing a melting temperature of $62^{\circ} \mathrm{C}$. By using three serial dilutions of cDNA, primer efficiencies were determined, only primers with efficiencies varying around $100 \%$ were used for analysis.

$0,5 \mu \mathrm{g}$ of total RNA was retro-transcribed using RevertAid $\mathrm{H}$ Minus First Strand cDNA Synthesis Kit (Thermo/Fermentas). Each PCR reaction was performed on $1 / 40$ of the CDNA obtained, using SSoFast EvaGreen Supermix (Bio-Rad) according to the manufacturer's instructions and Bio-Rad CFX-96 as detection system. All samples were analyzed in triplicates and from 3 independent biological RNA samples. For each sample, the levels of mRNAs were normalized using rp49 as a loading control. Normalized data then were used to quantify the relative levels of mRNA using the $\triangle \triangle C T$ method. qPCR was carried out using a CFX-96 Biorad instrument. Biological replicates represent independently grown and processed cells. Technical replicates represent multiple measurements of the same biological sample.

\section{Protein analysis}

Total protein lysates were prepared in lysis buffer containing protease inhibitors. Proteins were size-separated by SDSPAGE and transferred onto nitrocellulose or PDVF membranes (Biorad). For Western blot analysis, primary antibodies were anti-GFP (3H9) (1:1000, Chromotek), anti-mouse V5 (1:5000, Invitrogen), anti-mouse HA (1:5000, Covance) and anti-a-tubulin (AA4.3) (1:1000, Developmental Studies Hybridoma Bank).

\section{Protein Purifications}

Drosophila Pumilio domains (PUM-D1, PUM-D3, Pum-D1D3) fused to V5-6xHis were subcloned into pET 28a and pET26a vectors for protein expression in bacteria. Plasmids were transformed into BL21(DE3) competent cells and recombinant 
proteins were induced with $1 \mathrm{mM} \mathrm{IPTG}$ at $25^{\circ} \mathrm{C}$. Bacteria were lysed in lysis buffer $(500 \mathrm{mM} \mathrm{NaCl}, 50 \mathrm{mM}$ Tris-Cl, pH8.0, $0,1 \%$ Triton, Protease inhibitors). Samples were lysed by sonication, centrifuged twice at $12,000 \mathrm{rpm}$ for $15 \mathrm{~min}$, and the cleared supernatant was bound to Ni-NTA Superflow beads (Qiagen) by gravity filtration. Unbound proteins were washed with lysis buffer at $\mathrm{pH} 8.0$ supplemented with increasing amounts of imidazole $(5 \mathrm{mM}, 40 \mathrm{mM}, 60 \mathrm{mM})$. Recombinant proteins were eluted from beads in lysis buffer with 100-250 $\mathrm{mM}$ imidazole at $\mathrm{pH}$ 8.0. For recombinant proteins retained in inclusion bodies (PUM-D3), solubilization was done by including $6 \mathrm{M}$ urea in lysis buffer. All purified Pumilio recombinant proteins were dialized overnigth at $4^{\circ} \mathrm{C}$, against a final buffer (20mM Hepes, $200 \mathrm{mM} \mathrm{NaCl}, 5 \%$ Glicerol, $2 \mathrm{mM}$ DTT) and concentrated with appropriate MW cut-off Vivaspin columns (Merck). The concentration of purified proteins was determined by colorimetric assay (Bio-Rad DC Protein Assay) and verified by electrophoresis alongside of BSA standards with Coomassie staining.

\section{Immunoprecipitation of TAP-PUM from flies}

Extracts from adult flies heads were prepared as described in 48. After immunoprecipitation of TAP-PUM, total RNA was extract with Trizol and Xbp1 mRNA levels detected by RT-PCR using specific primers for each Xbp1 transcript.

\section{In vitro phosphorylation assays}

Ire1 phosphorylation assays were performed by incubation of purified hlre1 KR $(3,3 \mu \mathrm{g} / \mu \mathrm{l})$ with purified Pumilio protein (dPumD1, dPumD3, hPumFI) in IRE1 kinase buffer $(25 \mathrm{mM}$ HEPES, pH 7.5, 150mM NaCl, 5mM DTT, 5\% glicerol), containing either $10 \mu \mathrm{Ci}$ of $\gamma$-ATP $\left.{ }^{32} \mathrm{P}\right]$ for radioactive assays or cold ATP [2mM] for phostag immunoblot assays (in a total volume of reaction of 20 $\mu$ l). Inhibitors of IRE1 Kinase (Apy 29 $[2,5 \mu \mathrm{M} / \mu \mathrm{l}]$ and compound \#18 $[2,5 \mu \mathrm{M} / \mu \mathrm{l}])$ were pre-incubated with hIRE1 and all reactions were assembled on ice, prior to addition of ATP and incubation for $2 \mathrm{~h}$ at $25^{\circ} \mathrm{C}$. Phosphatase treatment with $\lambda \mathrm{PP}$ (NEB) or CIP (NEB) were performed after phosphorylation reactions, for $40 \mathrm{~min}$ at $30^{\circ} \mathrm{C}$. Each reaction was stopped by addition of SDS-PAGE loading buffer and run on pre-maid SDS-PAGE gels (Biorad). The autophosphorylation of hIRE1 KR was confirmed by western blot using a pSer/24 phospho-specific antibody (Genentech) and phosphorylated Pumilio proteins were detected using antimouse-V5 antibody (Invitrogen). In the case of kinase radioactive assays, gels were dried and kinase activity visualized by autoradiography.

\section{Phostag-gels}

S2 cells were lysed in CIP buffer $(100 \mathrm{mM} \mathrm{NaCl}, 50 \mathrm{mM}$ Tris$\mathrm{HCl} \mathrm{pH} \mathrm{7.9,10} \mathrm{mM} \mathrm{MgCl}, 1 \mathrm{mM}$ DTT), $1 \mathrm{mM} \mathrm{PMSF}, 0.1 \%$ NP40, protease inhibitor cocktail (Roche), and phosphatase inhibitor cocktail (Calbiochem). For CIP treatment phosphatase inhibitor cocktail was omitted, and lysate was incubated $37^{\circ} \mathrm{C}$ 60 min in 2 units CIP (NEB) per $50 \mu \mathrm{L}$ reaction containing $50 \mu \mathrm{g}$ of total protein. For $\lambda$-phosphatase (NEB) treatment, lysates were incubated with 1 unit of phosphatase for $30 \mathrm{~min}$ at $30^{\circ} \mathrm{C}$ in $\lambda$ phosphatase buffer. Lysates were cleared by centrifugation and subjected to SDS-PAGE. To detect phosphorylated Pumilio in SDS-PAGE, we used Phos-tag AAL-107 (Wako Chemicals $\mathrm{GmbH}$ ) according to the manufacturer's instruction 68,69 . Western blotting was performed using mouse anti-V5 (1:5000, Invitrogen), followed by the corresponding Horseradish Peroxidase (HRP) conjugated secondary antibodies (1:5000, GE Healthcare) and visualized using the ECL Plus Western Blotting detection system (GE Healthcare).

\section{dsRNA treatments}

RNAi was performed as described previously ${ }^{70}$. Primer pairs tailed with the T7 RNA polymerase promoter were used to amplify PCR fragments obtained from cDNA clones. PCR products with an average size of $600 \mathrm{bp}$ were then used as templates for dsRNA production with the T7 RiboMAX system (Promega). For transfection, $15 \mu \mathrm{g} / \mathrm{ml}$ dsRNA was added to S2 cells in 12-well plates, during 9 days to silence Drosophila Pumilio. mRNA depletion was confirmed by RT-PCR before further transfections.

\section{Immunofluorescence and confocal microscopy}

For Drosophila pupal dissections, white pre-pupae (0h pupa) were collected and maintained at $25^{\circ} \mathrm{C}$ until the required stage. Larval, pupal and adult eyes were dissected in 1xPBS, fixed in $1 \mathrm{xPBS}+4 \%$ Formaldehyde for 40 minutes at room temperature and washed 3 times with $1 \mathrm{xPBS}+0.3 \%$ Triton $X$ 100. Primary antibodies were incubated in $1 \times$ PBS, $1 \%$ BSA, $0.1 \%$ Tween $20,250 \mathrm{mM} \mathrm{NaCl}$ overnight at $4^{\circ} \mathrm{C}$. Samples were washed 3 times with $1 \times$ PBS $+0.3 \%$ Triton X-100 and incubated with appropriate secondary antibodies (from Jackson ImmunoResearch Laboratories) for 2 hours at room temperature. Samples were mounted in $80 \%$ glycerol in a bridge formed by two cover slips to prevent the samples from being crushed while analyzed on the confocal microscope (Leica TCS SP5, 63X magnification oil immersion lens).

\section{Xbp1 RNA cleavage assay}

T7 RNA was generated from pOT2-Xbp1, containing the ORF and UTR of Drosophila Xbp1. $1 \mu \mathrm{g}$ of RNA was digested at room temperature by $1 \mu \mathrm{g}$ of human IRE $1 \alpha \mathrm{KR}$ recombinant protein $(\sim 0.8 \mu \mathrm{M})$ for $45 \mathrm{~min}$ in RNA cleavage buffer (HEPES pH7.5 $20 \mathrm{mM} ; \mathrm{K}$ acetate $50 \mathrm{mM}$; $\mathrm{Mg}$ acetate $1 \mathrm{mM}$; TritonX-100 $0.05 \%(\mathrm{v} / \mathrm{v}))$. The total volume of the reaction is $25 \mu \mathrm{l}$. The digestion was then complemented by an equal volume of formamide and heated up at $70^{\circ} \mathrm{C}$ for 10 min to denature the RNA. The mixture was immediately placed on ice for $5 \mathrm{~min}$, and then $20 \mu \mathrm{l}$ was run on $3 \%$ agarose gel at $160 \mathrm{~V}$ for 1 hour at $4^{\circ} \mathrm{C}$. The PUM proteins were incubated with the RNA for 40 min on ice prior to RNA digestion.

\section{Statistical Methods}

All panels data are represented as mean \pm SEM, from at least three independent biological replicates experiments. All statistical comparisons for significance between control and experimental groups was calculated using a significance cut off $p<0.05$. and denoted by ${ }^{*} p<0.05,{ }^{* *} p<0.01$, and ${ }^{* * *} p<0.001$, based on two-tailed unpaired t-Student's test or one-way ANOVA followed by an appropriate post-hoc analysis. Statistical analyses were performed using GraphPad Prism 8 (GraphPad Software, Inc) and online resources (https:// astatsa.com/OneWay_Anova_with_TukeyHSD).

\section{AUTHOR CONTRIBUTIONS}

FC designed the study, performed the experiments, analyzed data and wrote the manuscript. CS constructed reagents for the Phostag assays and contributed to the RNA IP assays. ALT conducted the Xbp1 mRNA in vitro cleavage assays. SM provided the purified versions of hPUM1. PD performed the IF staining in Fig.2. PD and AA designed and supervised the study, analyzed data and wrote the manuscript. All authors read and edited the manuscript.

\section{ACKNOWLEDGMENTS}

We thank Aaron Goldstrohm for plasmids. We thank Yuh Nung Jan, Stefan Luschnig and André Gerber for Pumilio fly stocks. We thank David Ron and Heather Harding for providing the purified hIRE $1 \alpha \mathrm{KEN}, 4 \mu 8 \mathrm{C}$ and helpful discussions. This work 


\section{Preprint}

received funding by grants from the Fundação para a Ciencia e Tecnologia (PTDC/BIA-BCM/105217/2008; PTDC/SAUOBD/104399/2008; PTDC/BEX-BCM/1217/2012; FCT-ANR/ NEU-NMC/0006/2013; PTDC/NEU-NMC/2459/2014; SFRH/ BPD/93893/2013 and DL57/2016 to FC and SFRH/BD/ $130817 / 2017$ to CS). The project leading to these results has also received funding from 'la Caixa' Foundation (ID 100010434), under the agreement <LCF/PR/ HR17/52150018>.

\section{REFERENCES}

1. Ron, D. \& Walter, P. Signal integration in the endoplasmic reticulum unfolded protein response. Nat. Rev. Mol. Cell Biol. 8, 519-529 (2007).

2. Walter, P. \& Ron, D. The unfolded protein response: from stress pathway to homeostatic regulation. Science 334, 1081-1086 (2011).

3. Cox, J. S. \& Walter, P. A Novel Mechanism for Regulating Activity of a Transcription Factor That Controls the Unfolded Protein Response. Cell 87, 391-404 (1996).

4. Yoshida, H., Matsui, T., Yamamoto, A., Okada, T. \& Mori, K. XBP1 mRNA is induced by ATF6 and spliced by IRE1 in response to ER stress to produce a highly active transcription factor. Cell 107, 881-891 (2001).

5. Shen, X. et al. Complementary signaling pathways regulate the unfolded protein response and are required for $\mathrm{C}$. elegans development. Cell 107, 893903 (2001).

6. Calfon, M. et al. IRE1 couples endoplasmic reticulum load to secretory capacity by processing the XBP-1 mRNA. Nature 415, 92-96 (2002).

7. Uemura, A., Oku, M., Mori, K. \& Yoshida, H. Unconventional splicing of XBP1 mRNA occurs in the cytoplasm during the mammalian unfolded protein response. J. Cell. Sci. 122, 2877-2886 (2009).

8. Acosta-Alvear, D. et al. XBP1 Controls Diverse Cell Type- and Condition-Specific Transcriptional Regulatory Networks. Molecular Cell 27, 53-66 (2007).

9. Quenault, T., Lithgow, T. \& Traven, A. PUF proteins: repression, activation and mRNA localization. Trends in Cell Biology 21, 104-112 (2011).

10. Vazquez-Pianzola, P., Urlaub, H. \& Suter, B. Pabp binds to the osk 3'UTR and specifically contributes to osk mRNA stability and oocyte accumulation. Dev. Biol. 357, 404-418 (2011).

11. Webster, M. W., Stowell, J. A. \& Passmore, L. A. RNA-binding proteins distinguish between similar sequence motifs to promote targeted deadenylation by Ccr4-Not. Elife 8, W39 (2019).

12. Aragón, T. et al. Messenger RNA targeting to endoplasmic reticulum stress signalling sites. Nature 457, 736-740 (2009).

13. Yanagitani, K. et al. Cotranslational Targeting of XBP1 Protein to the Membrane Promotes Cytoplasmic Splicing of Its Own mRNA. Molecular Cell 34, 191-200 (2009).

14. Yanagitani, K., Kimata, Y., Kadokura, H. \& Kohno, K. Translational pausing ensures membrane targeting and cytoplasmic splicing of XBP1u mRNA. Science 331, 586-589 (2011).

15. Hollien, J. et al. Regulated Ire1-dependent decay of messenger RNAs in mammalian cells. The Journal of Cell Biology 186, 323-331 (2009).

16. Upton, J.-P. et al. IRE1 a cleaves select microRNAs during ER stress to derepress translation of proapoptotic Caspase-2. Science 338, 818-822 (2012).

17. Moore, K. \& Hollien, J. Ire1-mediated decay in mammalian cells relies on mRNA sequence, structure, and translational status. Mol. Biol. Cell
mbc.E15-02-0074 (2015). doi:10.1091/mbc.E15-020074

18. Gardner, B. M. \& Walter, P. Unfolded proteins are Ire1activating ligands that directly induce the unfolded protein response. Science 333, 1891-1894 (2011).

19. Ghosh, R. et al. Allosteric Inhibition of the IRE1a RNase Preserves Cell Viability and Function during Endoplasmic Reticulum Stress. Cell 158, 534-548 (2014).

20. Lu, M. et al. Opposing unfolded-protein-response signals converge on death receptor 5 to control apoptosis. Science 345, 98-101 (2014).

21. Coelho, D. S. \& Domingos, P. M. Physiological roles of regulated Ire1 dependent decay. frontiers in genetics 5, (2014).

22. Huang, H.-W., Zeng, X., Rhim, T., Ron, D. \& Ryoo, H. $D$. The requirement of IRE1-XBP1 in resolving physiological stress during Drosophila development. J. Cell. Sci. jcs.203612 (2017). doi:10.1242/ jcs.203612

23. Perron, G. et al. A General Framework for Interrogation of mRNA Stability Programs Identifies RNA-Binding Proteins that Govern Cancer Transcriptomes. CellReports 23, 1639-1650 (2018).

24. Guan, X. et al. PUM1 promotes ovarian cancer proliferation, migration and invasion. Biochem. Biophys. Res. Commun. 497, 313-318 (2018).

25. Dai, $\mathrm{H}$. et al. PUM1 knockdown prevents tumor progression by activating the PERK/elF2/ATF4 signaling pathway in pancreatic adenocarcinoma cells. Cell Death Dis 10, 595 (2019).

26. Bohn, J. A. et al. Identification of diverse target RNAs that are functionally regulated by human Pumilio proteins. Nucleic Acids Res. 46, 362-386 (2018).

27. Forbes, A. \& Lehmann, R. Nanos and Pumilio have critical roles in the development and function of Drosophila germline stem cells. Development 125, 679-690 (1998)

28. Naudin, C., Hattabi, A., Michelet, F., Blood, A. M.N.2017. PUMILIO/FOXP1 signaling drives expansion of hematopoietic stem/progenitor and leukemia cells. Am Soc Hematology doi:10.1182/blood-2016-10

29. Shigunov, P. et al. PUMILIO-2 is involved in the positive regulation of cellular proliferation in human adipose-derived stem cells. Stem Cells Dev. 21, 217227 (2012).

30. Mak, W., Fang, C., Holden, T., Dratver, M. B. \& Lin, H. An Important Role of Pumilio 1 in Regulating the Development of the Mammalian Female Germline. Biol. Reprod. 94, 134 (2016).

31. Vessey, J. P. et al. Mammalian Pumilio 2 regulates dendrite morphogenesis and synaptic function. Proc. Natl. Acad. Sci. U.S.A. 107, 3222-3227 (2010).

32. Miles, W. O., Tschöp, K., Herr, A., Ji, J.-Y. \& Dyson, N. J. Pumilio facilitates miRNA regulation of the E2F3 oncogene. Genes \& Development 26, 356-368 (2012).

33. Driscoll, H. E., Muraro, N. I., He, M. \& Baines, R. A. Pumilio-2 regulates translation of Nav1.6 to mediate homeostasis of membrane excitability. J. Neurosci. 33, 9644-9654 (2013)

34. Gennarino, V. A. et al. Pumilio1 haploinsufficiency leads to SCA1-like neurodegeneration by increasing wild-type Ataxin1 levels. Cell 160, 1087-1098 (2015).

35. Gehrke, S. et al. PINK1 and parkin control localized translation of respiratory chain component mRNAs on mitochondria outer membrane. Cell Metab. 21, 95108 (2015)

36. Goldstrohm, A. C., Hall, T. M. T. \& McKenney, K. M. Post-transcriptional Regulatory Functions of Mammalian Pumilio Proteins. Trends Genet. 34, 972990 (2018)

37. Lehmann, R. \& Nüsslein-Volhard, C. Involvement of the pumilio gene in the transport of an abdominal 


\section{Preprint}

signal in the Drosophila embryo. Nature 329, 167-170 (1987)

38. Wharton, R. P., Sonoda, J., Lee, T., Patterson, M. \& Murata, Y. The Pumilio RNA-binding domain is also a translational regulator. Molecular Cell 1, 863-872 (1998).

39. Menon, K. P. et al. The translational repressor Pumilio regulates presynaptic morphology and controls postsynaptic accumulation of translation factor elF4E. Neuron 44, 663-676 (2004).

40. De Jesus-Olmo, L. A. et al. Pumilio Regulates Sleep Homeostasis in Response to Chronic Sleep Deprivation in Drosophila melanogaster. Front. Neurosci. 14, (2020).

41. Wharton, R. P. \& Aggarwal, A. K. mRNA regulation by Puf domain proteins. Sci. STKE 2006, pe37-pe 37 (2006)

42. Arvola, R M et al. Unique repression domains of Pumilio utilize deadenylation and decapping factors to accelerate destruction of target mRNAs. Nucleic Acids Res. 48, 1843-1871 (2020).

43. Weidmann, C. A., Raynard, N. A., Blewett, N. H., Van Etten, J. \& Goldstrohm, A. C. The RNA binding domain of Pumilio antagonizes poly-adenosine binding protein and accelerates deadenylation. RNA 20, 1298-1319 (2014).

44. Salazar, A. M., Silverman, E. J., Menon, K. P. \& Zinn, K. Regulation of Synaptic Pumilio Function by an Aggregation-Prone Domain. J. Neurosci. 30, 515 (2010).

45. Miller, M. A. \& Olivas, W. M. Roles of Puf proteins in mRNA degradation and translation. Wiley Interdiscip Rev RNA 2, 471-492 (2011).

46. Bunch, T. A., Grinblat, Y. \& Goldstein, L. S. Characterization and use of the Drosophila metallothionein promoter in cultured Drosophila melanogaster cells. Nucleic Acids Res. 16, 10431061 (1988).

47. Cairrao, F., Halees, A. S., Khabar, K. S. A., Morello, D. \& Vanzo, N. AU-rich elements regulate Drosophila gene expression. Molecular and Cellular Biology 29, 2636-2643 (2009).

48. Gerber, A. P., Luschnig, S., Krasnow, M. A., Brown, P. O. \& Herschlag, D. Genome-wide identification of mRNAs associated with the translational regulator PUMILIO in Drosophila melanogaster. Proceedings of the National Academy of Sciences 103, 4487-4492 (2006).

49. Ryoo, H. D., Domingos, P. M., Kang, M. J. \& Steller, $\mathrm{H}$. Unfolded protein response in a Drosophila model for retinal degeneration. EMBO J. 26, 242-252 (2007).

50. Weidmann, C. A. \& Goldstrohm, A. C. Drosophila Pumilio protein contains multiple autonomous repression domains that regulate mRNAs independently of Nanos and brain tumor. Molecular and Cellular Biology 32, 527-540 (2012).

51. Coelho, D. S. et al. Xbp1-independent Ire1 signaling is required for photoreceptor differentiation and rhabdomere morphogenesis in Drosophila. CellReports 5, 791-801 (2013).

52. Ye, B. et al. Nanos and Pumilio are essential for dendrite morphogenesis in Drosophila peripheral neurons. Curr. Biol. 14, 314-321 (2004).

53. Kedde, M. et al. A Pumilio-induced RNA structure switch in p27-3' UTR controls miR-221 and miR-222 accessibility. Nature Cell Biology 12, 1014-1020 (2010).

54. Gnad, F., Gunawardena, J. \& Mann, M. PHOSIDA 2011: the posttranslational modification database. Nucleic Acids Res. 39, D253-D260 (2011).

55. Korennykh, A. V. et al. The unfolded protein response signals through high-order assembly of Ire1. Nature 457, 687-693 (2008).
56. Harrington, P. E. et al. Unfolded Protein Response in Cancer: IRE1a Inhibition by Selective Kinase Ligands Does Not Impair Tumor Cell Viability. ACS Med. Chem. Lett. 6, 68-72 (2014).

57. Cross, B. et al The molecular basis for selective inhibition of unconventional mRNA splicing by an IRE1-binding small molecule. PNAS 109, E869-E878 (2012).

58. Hollien, J. \& Weissman, J. S. Decay of endoplasmic reticulum-localized mRNAs during the unfolded protein response. Science 313, 104-107 (2006).

59. Gaddam, D., Stevens, N. \& Hollien, J. Comparison of mRNA localization and regulation during endoplasmic reticulum stress in Drosophila cells. Mol. Biol. Cell 24, 14-20 (2013).

60. Majumder, M. et al. A novel feedback loop regulates the response to endoplasmic reticulum stress via the cooperation of cytoplasmic splicing and mRNA translation. Molecular and Cellular Biology 32, 9921003 (2012).

61. Chang, T.-K. et al. Coordination between Two Branches of the Unfolded Protein Response Determines Apoptotic Cell Fate. Molecular Cell 71, 629-636.e5 (2018).

62. Peschek, J. \& Walter, P. tRNA ligase structure reveals kinetic competition between non-conventional mRNA splicing and mRNA decay. Elife 8, 213 (2019).

63. Naudin, C. et al. PUMILIO/FOXP1 signaling drives expansion of hematopoietic stem/progenitor and leukemia cells. Blood blood-2016-10-747436-35 (2017). doi:10.1182/blood-2016-10-747436

64. Uyhazi, K. E. et al. Pumilio proteins utilize distinct regulatory mechanisms to achieve complementary functions required for pluripotency and embryogenesis. Proc. Natl. Acad. Sci. U.S.A. 3, 201916471 (2020)

65. Saitoh, A., Takada, Y., Horie, M. \& Kotani, T. Pumilio1 phosphorylation precedes translational activation of its target mRNA in zebrafish oocytes. Zygote 26, 372-380 (2018).

66. Ota, R., Kotani, T. \& Yamashita, M. Biochemical characterization of Pumilio1 and Pumilio2 in Xenopus oocytes. Journal of Biological Chemistry 286, 28532863 (2011).

67. Golic, K. G. Site-specific recombination between homologous chromosomes in Drosophila. Science 252, 958-961 (1991).

68. Kinoshita-Kikuta, E., Kinoshita, E., Matsuda, A. \& Koike, T. Tips on improving the efficiency of electrotransfer of target proteins from Phos-tag SDSPAGE gel. Proteomics 14, 2437-2442 (2014).

69. Kinoshita, E., Kinoshita-Kikuta, E. \& Koike, T. Separation and detection of large phosphoproteins using Phos-tag SDS-PAGE. Nature Protocols 4, 1513-1521 (2009)

70. Clemens, J. C. et al. Use of double-stranded RNA interference in Drosophila cell lines to dissect signal transduction pathways. Proceedings of the National Academy of Sciences 97, 6499-6503 (2000). 


\section{Xbp1-GFP- 3'UTR}

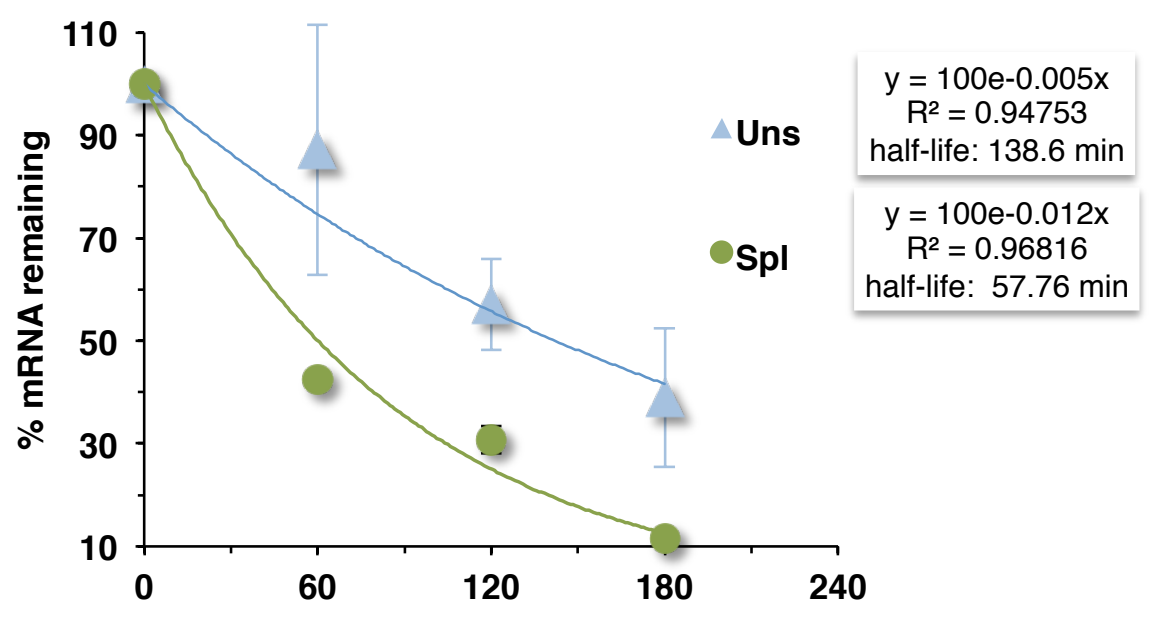

Time (min) after ActD treatment

Figure S1- Xbp1 3'UTR Unspliced and 3'UTR Spliced differ in their stability effect

Stability of the GFP reporters fused with Xbp1 3'UTR ${ }^{\text {spliced }}$ or 3'UTR ${ }^{\text {unspliced }}$ was assessed by quantitative RT-PCR (qRT-PCR), using primers specific for GFP and rp49 mRNAs (control). The levels of mRNA reporter were normalized to those of rp49 mRNA, and averages and standard deviations from three independent experiments are plotted. 3'UTR ${ }^{\text {unspliced }}$ shows a higher stability effect of the reporter half-life ( 2 fold stabilization) relatively to the spliced form. 
bioRxiv preprint doi: https://doi.org/10.1101/2021.02.08.430300; this version posted February 8, 2021. The copyright holder for this preprint (which was not certified by peer review) is the author/funder, who has granted bioRxiv a license to display the preprint in perpetuity. It is made available under aCC-BY 4.0 International license.

\section{Preprint}

a

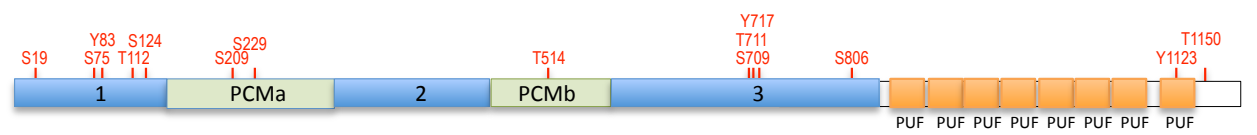

Hu PUM1 A (S2-I 1186)

$118 \mathrm{kDa}$

Hu PUM1 B (S2-S827)

$82,5 \mathrm{kDa}$

Hu PUM1 C (G828-I 1186)

$35,8 \mathrm{kDa}$

b
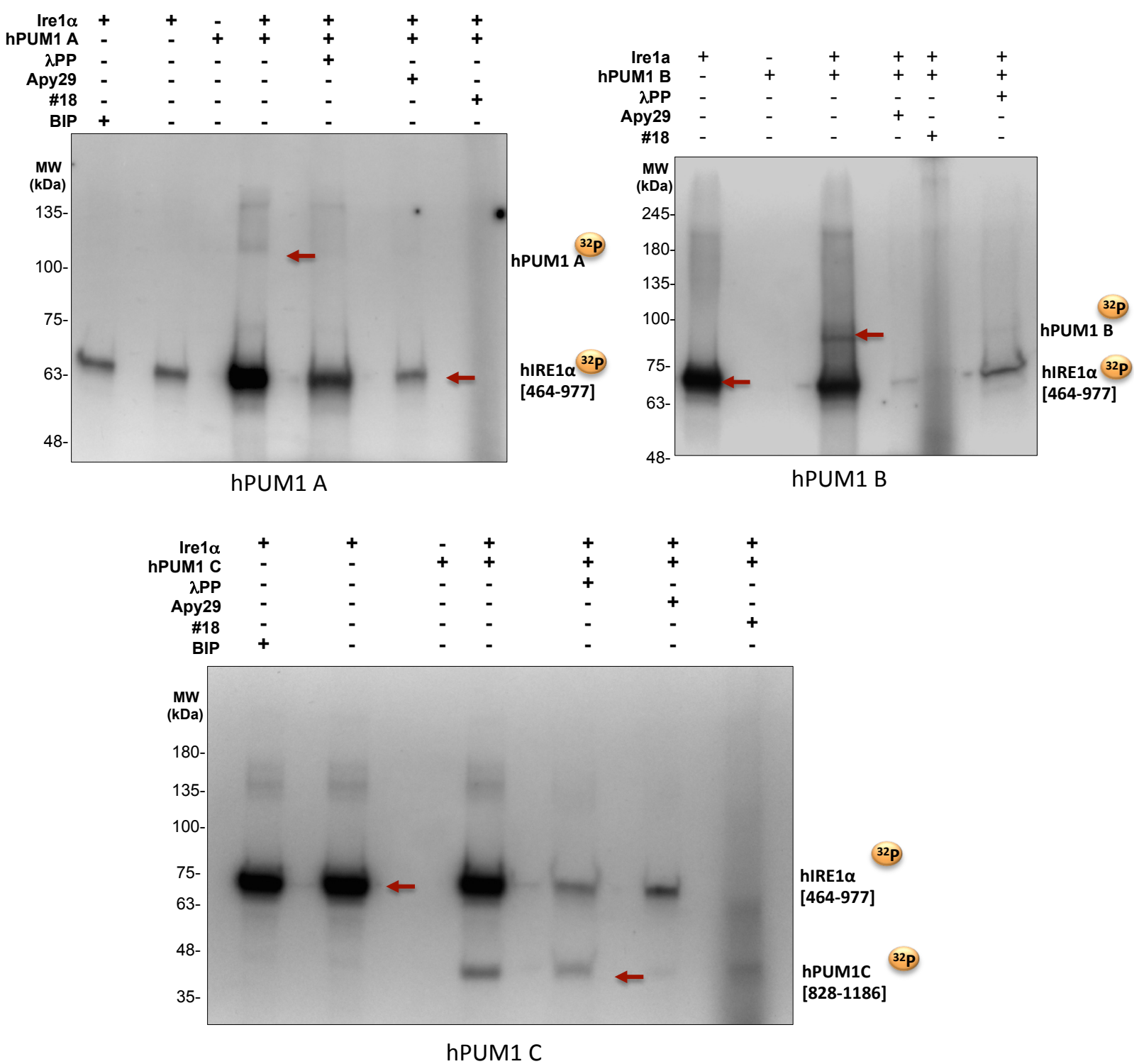

Figure S2 hIRE1 KR domain phosphorylates hPUM1 in vitro

a) Schematic representation of domains and putative phosphorylation sites present in Human PUM1.

b) in vitro radioactive kinase assay with $\left.\gamma-{ }^{32} \mathrm{P}\right] \mathrm{ATP}$ of purified hPUM1 forms incubated with hIRE1 KR domain. Specificity of phosphorylation was monitored by treatment with lambdaPP or incubation with specific inhibitors of IRE1 kinase activity (Apy 29 and \#18). Arrows express hPUM1 phosphorylated forms corresponding to the expected MW of each purified protein. Treatment with kinase inhibitors decreased the amount of detected radioactive protein bands. 
a

\begin{tabular}{|c|c|c|c|c|c|c|c|c|c|}
\hline \multirow[b]{2}{*}{ hlre1 $\alpha$} & \multirow[b]{2}{*}{+} & \multirow[b]{2}{*}{ - } & \multicolumn{3}{|c|}{ hPUM1 C } & \multicolumn{4}{|c|}{ dPUM D3 } \\
\hline & & & - & + & - & + & - & - & + \\
\hline hIRE1KD & - & + & - & - & - & - & - & + & - \\
\hline hPUM1 C & - & - & + & + & + & - & - & - & - \\
\hline dPumD3 & - & - & - & - & - & + & + & + & + \\
\hline$\lambda P P$ & - & - & - & - & + & - & - & - & + \\
\hline
\end{tabular}

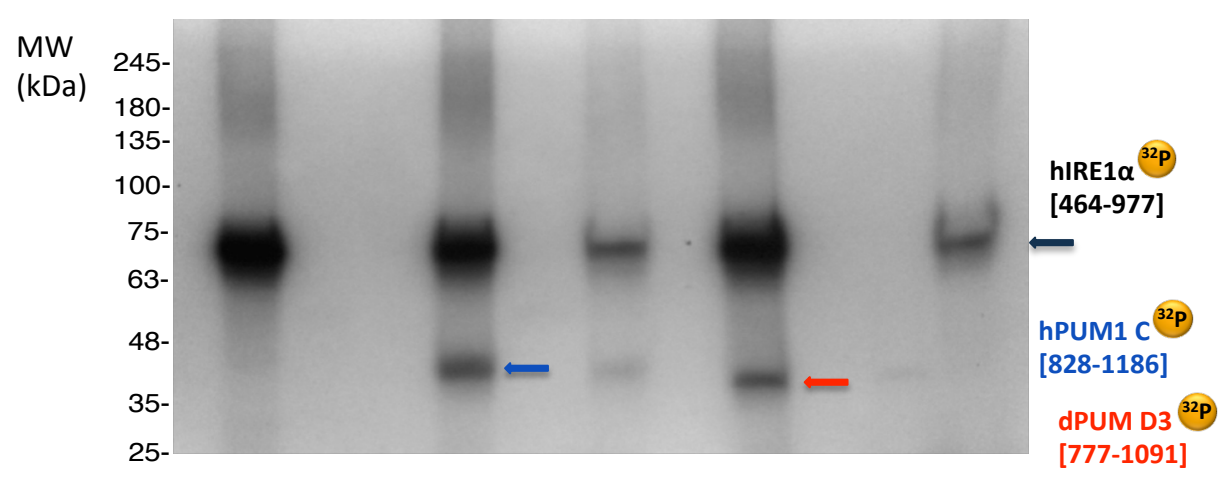

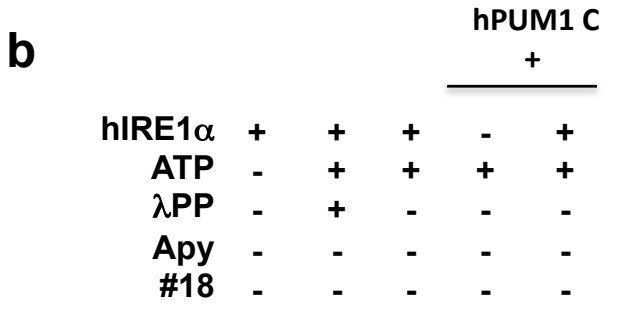

M
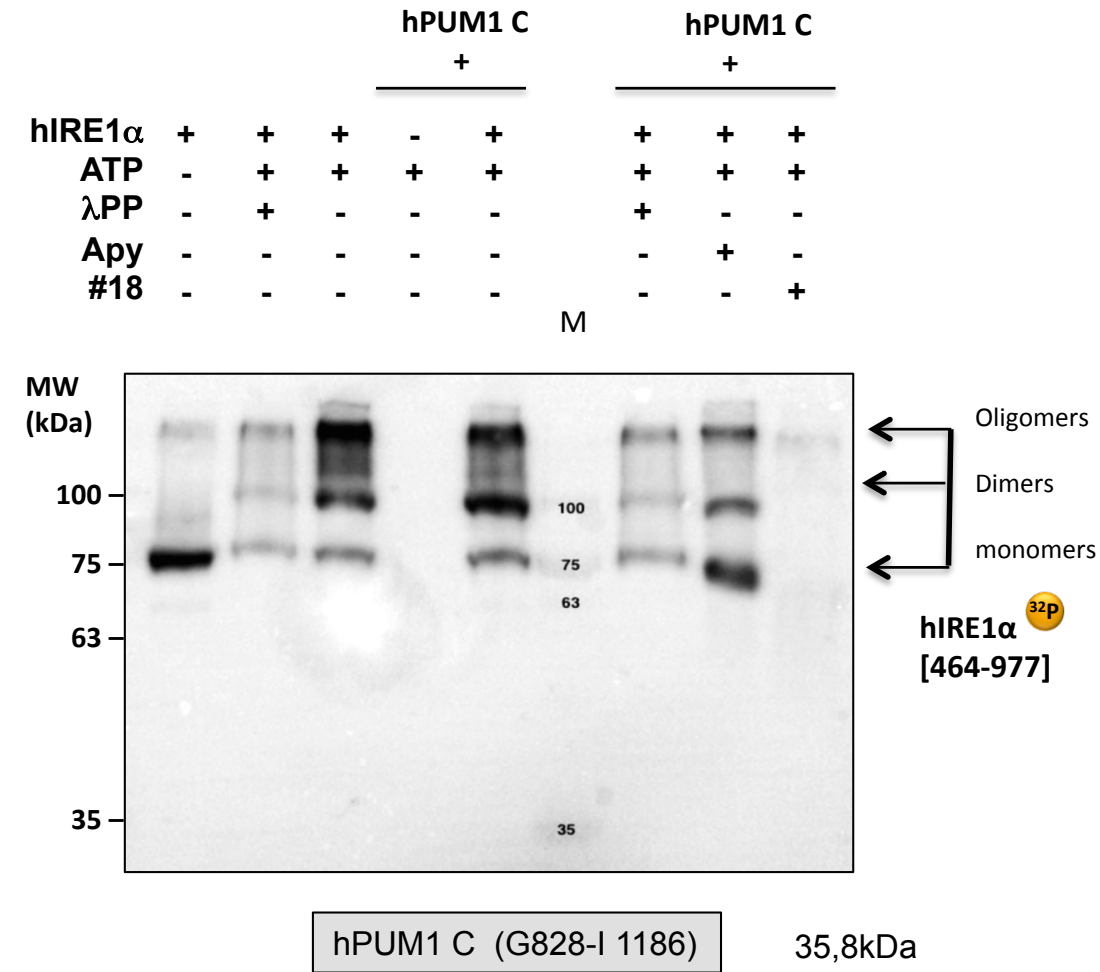

Figure S3 Validation of in vitro phosphorylation hPUM1-C and dPUM-D3

a) In vitro phosphorylation hPUM1-C domain and dPUM-D3 domain by hIRE1 KR using the control kinase-dead Ire1 (hIRE1KD, $\mathrm{D} 688 \mathrm{~N})$. Assays were conducted as described before. Arrows denote phosphorylated forms of hPUM-C (Blue arrow) and dPUMD3 purified proteins (red arrow). Autophosphorylation of hIRE KR is denoted by a black arrow.

b) Phostag immunoblot of phosphorylation of hPUM-C with an antibody specific for phosphorylated IRE1(anti-rabbit PhosphoIre1). Specificity of phosphorylation was monitored by treatment with $\lambda$ PP or incubation with specific inhibitors of IRE1 kinase activity (Apy 29 and compound \#18) and a reaction lacking ATP (first lane). The phosphorylation state of hIRE1 KR is decreased in control reactions as expected comparatively to the reactions containing hIRE1+ATP or hIRE1 + hPUM-C + ATP. An additional control was made by conducting a kinase assay of hPUM-C without incubation with hIRE1 KR domain. M - Protein molecular weight marker lane. 